NBER WORKING PAPER SERIES

\title{
DO DEMOGRAPHIC CHANGES AFFECT RISK PREMIUMS? EVIDENCE FROM INTERNATIONAL DATA
}

\author{
Andrew Ang \\ Angela Maddaloni \\ Working Paper 9677 \\ http://www.nber.org/papers/w9677

\begin{abstract}
NATIONAL BUREAU OF ECONOMIC RESEARCH
1050 Massachusetts Avenue

Cambridge, MA 02138
\end{abstract}

May 2003

We are grateful to John Donaldson and Paolo Siconolfi for helpful discussions and suggestions. We thank Geert Bekaert, Philip Davis, John Fell, Hans-Joachim Klöckers, Cam Harvey, Jim Poterba, Abigail Tay, and seminar participants at Columbia University for helpful comments. We thank Francesca Di Iorio for providing most of the population data and Alan Taylor for the macroeconomic data. We are grateful to an anonymous referee for providing very helpful comments. This paper represents the authors' personal opinions and does not necessarily reflect the views of the European Central Bank. The views expressed herein are those of the authors and not necessarily those of the National Bureau of Economic Research.

(C)2003 by Andrew Ang and Angela Maddaloni. All rights reserved. Short sections of text not to exceed two paragraphs, may be quoted without explicit permission provided that full credit including Cnotice, is given to the source. 
Do Demographic Changes Affect Risk Premiums? Evidence from International Data Andrew Ang and Angela Maddaloni

NBER Working Paper No. 9677

May 2003

JEL No. G12, G15, J10, P46

\section{ABSTRACT}

We examine the link between equity risk premiums and demographic changes using a very long sample over the twentieth century for the US, Japan, UK, Germany and France, and a shorter sample covering the last third of the twentieth century for fifteen countries. We find that demographic variables significantly predict excess returns internationally. However, the demographic predictability found in the US by past studies for the average age of the population does not extend to other countries. Pooling international data, we find that, on average, faster growth in the fraction of retired persons significantly decreases risk premiums. This demographic predictability of risk premiums is strongest in countries with well-developed social security systems and lesser-developed financial markets.

Andrew Ang

Columbia Business School

805 Uris Hall

3022 Broadway

New York, NY 10027

and NBER

aa610@columbia.edu
Angela Maddaloni

European Central Bank

Kaiserstrasse 29, D-60311

Frankfurt am Main

Germany

angela.maddaloni@ecb.int 


\section{Introduction}

During the 1990's, the baby boom generation (those born roughly in the two decades following World War II) entered its peak savings years. Individuals aged between 40 and 60 years old are the prime savers of the economy in the US and this age class is projected to rise until roughly 2010 and then decline. Several theoretical models have argued that the baby boom generation was a contributing factor to the high stock returns and the large increase in stock prices observed from 1990 to $1999 .{ }^{1}$ Some, such as Abel (2001b), argue that as the baby boomers retire, asset prices are likely to fall. Thus, understanding the effect the baby boomer cohort has on current and future asset returns is important for economic policy, social planning and social welfare issues. In this paper, we investigate the link between equity risk premiums and demographic changes in several countries. We contribute to the debate on expected returns and demography in a number of ways.

First, we construct long data samples covering most of the twentieth century for the largest five developed countries (France, Germany, Japan, UK and US). In the US, there has been only one baby boom shock in the past 40 years, but there have been demographic changes throughout the whole twentieth century. Linking the increase in asset prices in the US with only the high returns in the 1990's may correspond to only one, non-representative, observation. Focusing on this one observation opens up the possibility of data mining regarding inference of demographic predictability of expected returns. Moreover, since demography is a slowly evolving variable, testing for low-frequency changes in expected returns should be done with long time-series.

We use three explanatory variables to summarize dynamic demographic composition: the average age of the population above 20 years old, the fraction of adults over age 65, and the proportion of the population in the working ages 20-64. While levels of these variables are quite highly correlated across countries, changes in these demographic measures and average returns across the G5 countries are lowly correlated, so observing population changes and expected returns in these markets gives extra information which effectively increases our sample size.

Second, we construct a fairly large cross-sectional sample of 15 countries, covering most of the developed markets, similar to Erb, Harvey and Viskanta (1997). This data covers the last third of the twentieth century. While this second data set is much shorter, it provides a large sample of cross-sectional variation in demographic experience and expected returns.

\footnotetext{
${ }^{1}$ Mankiw and Weil (1989) make a similar argument trying to explain the rise of real estate prices in the late 1970's and early 1980's.
} 
Third, we use an econometric framework which adjusts for overlapping observations and heteroskedasticity by using Hodrick (1992) standard errors. These standard errors have good small sample properties and account for the moving average structure induced by using overlapping observations when looking at long-horizon returns (see Hodrick 1992; and Ang and Bekaert 2001). Using standard OLS, Newey-West (1987) or Hansen-Hodrick (1980) standard errors to judge predictability, especially over long horizons, may cause severe size biases. In particular, improper inference leads to over-rejection of the null hypothesis of constant expected returns. If correct inference is made using appropriate standard errors, there is no reason to restrict the data to be non-overlapping. Thus, our analysis uses all the available data, for most efficient estimation and most powerful tests. In contrast, Poterba (2001) uses 5-year nonoverlapping returns. We test predictability of the risk premium over horizons of 1 year, 2 years and 5 years.

Finally, we pool the cross-sectional information of both our long time-series over the G5 countries and our larger sample of 15 countries to jointly estimate the predictability coefficients. In this procedure, we specify each country to have its own (constant) expected return as the null hypothesis. We use the cross-sectional data to estimate the demographic predictability coefficients over several horizons, and conduct statistical inference with heteroskedastic-robust standard errors. Indeed, pooling the cross-sectional data significantly increases statistical power.

We find that demographic changes do indeed predict risk premiums internationally. However, the particular relationship between changes in average age and risk premiums in the US, which Bakshi and Chen (1994) and others find, is unique to the US and is not replicated in other countries. While changes in the average age of the population have no forecasting power in international data, the change in the proportion of retired adults is a significant predictor of excess returns. However, unlike the US experience, increases in the retired proportion of the population, as a fraction of the total adult population, decrease excess returns.

This result is somewhat surprising since retired people must finance their consumption entirely from financial wealth. Equities have larger aggregate risk, so the extant class of standard overlapping generations (OLG) models (for example, see Constantinides, Donaldson and Mehra 2002), predict that retirees should diversify their holdings and hold largely risk-free assets. In OLG models, when larger proportions of agents retire, they dis-save, and sell their assets not bequeathed to the next generation to fund their consumption. If these agents affect asset prices by selling their assets, asset prices would be pushed down and expected returns would increase. 
However, under special circumstances, our results may be consistent with theoretical models with idiosyncratic labor shocks. For example, Storesletten, Telmer and Yaron (2001) extend the Constantinides and Duffie (1996) model with idiosyncratic labor risk to include a retirement state for agents, where they receive no income shocks. In this extension, since retirees face no labor market risk, they are less averse to bearing aggregate risk and hold substantial amounts of equities. Such an economy with an increasing share of old people would see decreasing risk premiums. Once Storesletten, Telmer and Yaron introduce trading between young, middle-aged and old people, the portfolio implications look very similar to the standard OLG models, where middle-aged people hold most of the equities and retirees sell equities and mostly hold bonds. However, while the proportion of equities held by older people is substantially reduced, their calibrations show that retirees can still hold up to $30 \%$ of their portfolios in equities. A future extension of the Storesletten, Telmer and Yaron (2001) model to include demographic shifts might show that a society with a growing fraction of elderly people could potentially lead to decreasing risk premiums.

To further describe which characteristics of countries are driving the demographic predictability of risk premiums, we investigate if our results of increasing growth rates of retirees decreasing future excess returns are related to different levels of social security benefits or to different levels of participation in securities markets across countries. These factors influence the saving-investment choice of economic agents, especially retirees. We find that the pattern of demographic predictability is the same across countries with smaller or larger social security benefits, or well or less developed financial markets. However, demographic predictability of risk premiums is strongest for countries with larger social security benefits and less developed financial markets. These are also countries where equity participation has traditionally been low.

There have been few other empirical studies exploring the link between demography and risk premiums, and most of these focus on the US. ${ }^{2}$ Some studies using international data include Erb, Harvey and Viskanta (1997), Brooks (1998), Poterba (2001) and Davis and Li (2002). Erb, Harvey and Viskanta (1997) consider the predictability of demographic variables on asset returns in a large cross-section of developed markets, but with a short time series. They focus on predictability of total equity returns, rather than equity risk premiums, do not compute robust standard errors, or pool cross-sectional data. Brooks (1998) examines demography and equity

\footnotetext{
${ }^{2}$ See Bakshi and Chen (1994), Yoo (1994b), Bergantino (1998) and Goyal (2002).
} 
prices in the OECD nations over the post-war time period, but focuses on asset price levels rather than returns. Using information from the Survey of Consumer Finances, Poterba (2001) investigates the relationship between age and the demand for financial assets. His analysis is mainly limited to the US, but in the last part of the paper he explores time-series relationships between demographic change and asset returns in Canada and the UK, and finds little evidence of predictability of asset returns by demographic variables in these countries. All these studies do not conduct pooled cross-sectional estimations using international data over long horizons, nor do they compute robust standard errors.

The remainder of the paper is organized as follows. Section 2 presents the theoretical and empirical framework. Section 3 describes the data and shows how pooling international data leads to improvements in power. Section 4 presents the core findings on the demographic predictability of risk premiums. In Section 5, we examine the relationship between demography, social security and the relative degree of financial market development. Section 6 concludes.

\section{Theoretical and Empirical Framework}

\subsection{Theoretical Motivation}

The impact of demographic factors on asset prices has usually been theoretically modelled using an OLG framework. ${ }^{3}$ We briefly outline two recent examples of this literature to show how demographic changes can be related to the equity premium. Our exposition also highlights several ways in which demographic variables can impact risk premiums not generally considered in the simple theoretical models, but which we include in our empirical work.

The first example is Donaldson and Maddaloni (2002), who extend the OLG model of Constantinides, Donaldson and Mehra (2002) to include an exogeneous and fixed population growth rate $n$. Each generation born into the economy lives for three periods: young, middle-aged and old (or retired). The fraction of young people in the population is an increasing function of $n$, while the fraction of middle-aged and of old people are inversely related to its value. This allows different values of the population growth rate to give rise to different age distributions of the population. There are two financial assets, equity and risk-free bonds, in the economy and

\footnotetext{
${ }^{3}$ See the OLG models of Yoo (1994a), Brooks (2002a and b), Constantinides, Donaldson and Mehra (1998), Abel (2001a and 2001b, 2003), Donaldson and Maddaloni (2002), Luo (2000) and Goyal (2002).
} 
their supply also grows at the same rate $n$ as the population. ${ }^{4}$

Calibrated simulations of the model show that the risk premium is a decreasing function of $n$, but the effect of demographic changes on the value of the risk premium is generally small. The rationale behind this result is that equity become less attractive relative to bonds as population growth rises, because dividends in the Donaldson and Maddaloni (2002) model are a residual payment after subtracting wages and bond interest payments from output. As population growth rises, the claim of young people on output through wages increases, causing dividends to fall and causing equity to become less attractive than bonds. Hence, the required equity premium decreases.

This result is qualitatively similar to Brooks (2002a), who models a production-based economy rather than an exchange-based economy. In Brooks' model, agents live for four periods: childhood, young working age, old working age, and retirement. Young workers provide for their own consumption as well as for their children. In retirement, agents consume their savings and receive social security benefits indexed to current wages. The economy has two assets, a risk-free bond and risky capital, and the aggregate population growth rate is stochastic. Calibrating the model to match the US baby boom, Brooks forecasts that as the baby boomers retire, returns on both stocks and bonds are driven down by approximately 100 basis points. The effects of demographic change on risk premiums are very small, though, because of the low risk premium in the Brooks (2002a) model. Imposing borrowing constraints on young people, like those imposed by Constantinides, Donaldson and Mehra (2002), can increase the risk premium substantially to the value observed in data (see Brooks 2002b).

The OLG models all share the feature that demographic shocks affect asset returns even in economies where rational agents anticipate future population growth. Another general characteristic of OLG models incorporating demographic changes is the assumption that people sell their financial assets in order to consume when retired. In this framework, an ageing population generally implies a decrease of asset prices (both equity and bonds) and an increase of required expected excess returns. In Abel (2001b), a bequest motive is included in the model, but this is shown not to overturn the basic conclusions, at least for generally accepted calibrations.

Population dynamics can potentially drive the risk premium in several additional ways rather

\footnotetext{
${ }^{4}$ Despite this latter assumption, aggregate population growth rates still affect the value of risk premiums. Relaxing the link between the supply of financial assets and population growth rates potentially produces even larger effects.
} 
than just focusing on shocks to aggregate population growth. While Donaldson and Maddaloni (2002) assume that total population growth determines the cross-sectional population profile, in reality, it is possible that total population growth may be only one determinant of changes in the cross-sectional age profile of the population due to immigration and other channels. Changes in the demographic cross-section may have large effects on financial prices.

The existence of a relationship between equity premiums and cross-sectional population distribution is also theoretically supported in models incorporating some aspects of social security. For example, Campbell et al. (2001) assume that during working years, an individual must save a fraction of current labor income as illiquid retirement wealth that is converted into a riskless annuity after retirement. In this model, returns on financial assets are crucially affected by the relative proportions of working people and retirees. Goyal (2002) also shows that inflows (net new investments) in the stock market are directly related to changes, rather than static levels, in the demographic structure of the population.

In our empirical work, we examine several measures of different cohort growth rates in the demographic cross-sectional profile. In particular, we investigate the empirical relationship between excess returns and the growth of the fraction of people belonging to the age classes of the middle-aged (working) and old. Statistically, levels of demographic variables are also unit root, while changes of growth rates of demographic variables are more stationary. Hence, we examine log changes in the demographic variables of interests as predictors of risk premium. We denote these variables with " $d$ " prefixes.

Risk aversion itself may depend on demographic variables. Bakshi and Chen (1994), for example, find empirical evidence that an investor's relative risk aversion increases with age. While earlier studies based on the Survey of Consumer Finances, like Lampman (1962), found similar evidence, more recent work finds richer results at a cross-sectional level. In particular, Poterba (2001) finds supporting evidence that age is indeed related to risk tolerance, but this relationship is not monotonic. This might suggest that simple summary measures used by previous authors, such as the average age and the median age of the population may not be appropriate when studying the impact of demographics on asset pricing. These aggregate measures may also mask changes in cross-sectional population structure. In contrast, we also use several different cohort population measures as predictor variables.

Demographic changes may affect asset returns through several indirect ways. For example, Abel (2001b) comments that demography affects the composition of agents in the economy 
and their risk-sharing abilities. Ameriks and Zeldes (2001) show that households' portfolios vary with age, so demography is related to limited equity participation and non-participation, which affects expected returns and return variability, as Allen and Gale (1994) demonstrate. To further examine the relationship between demography and risk premiums, we examine how demographic predictability may change across countries with different social security systems (economies with different risk-sharing profiles) and different financial market development (economies with different financial market participation). Even in small open countries (like Australia and Belgium, for example), we might expect that demography is related to risk premiums, since even in these countries there is a pronounced home-bias, and low stock market participation (see, for example, Tesar and Werner 1995; and Guiso, Haliasos and Jappelli 2000).

\subsection{Empirical Framework}

In order to empirically investigate the relationship between expected returns and demographic variables we run regressions of the form:

$$
E_{t}\left[y_{t+1}\right]=\alpha+\beta^{\prime} z_{t}
$$

$y_{t+1}$ is the log excess return in period $(t+1)$, calculated as the difference between the continuously compounded total return of the stock market index and the continuously compounded return on a risk-free asset, and $z_{t}$ includes demographic variables and other, non demographic known predictor variables. We work with several demographic measures. The first is the fraction of people over 65 years old, called \%age65, a proxy for the percentage of retired people; the second is the percentage of people in the age class [20-64], called \%working, a proxy for the work force population. We consider also the average age of adult population, called age, calculated as the weighted average age of individuals over 20 years old, which is the same measure Bakshi and Chen (1994) employ.

Under the null that $\beta=0$ in equation (1), expected excess returns are constant. To empirically test the predictability of the equity premium over $k$ periods we use the regression:

$$
\tilde{y}_{t+k}=\alpha+\beta^{\prime} z_{t}+\epsilon_{t+k, k}
$$

where $\tilde{y}_{t+k}=(1 / k)\left(y_{t+1}+y_{t+2}+\cdots+y_{t+k}\right)$ is the annualized $k$-period excess return for the aggregate stock market, where all annual excess returns $y_{t+1}$ are continuously compounded. The error terms $\epsilon_{t+k, k}$ have an $M A(k-1)$ form because of over-lapping observations. 
We first run regressions with only one explanatory demographic variable. In this first set of regressions, $z_{t}$ in equation (2) is either $z_{t}=$ dage $_{t-1}, z_{t}=d \%$ age $65_{t-1}$, or $z_{t}=d \%$ working $g_{t-1}$, the annual growth rates of the demographic variables. The RHS variables are lagged by one year to ensure they are observable at time $t$. The literature has found other predictor variables, which have proved to explain movements in equity returns. In a second set of regressions, we control for other explanatory variables on the RHS of (2) by adding consumption growth dcons $_{t}$ and the term spread term $_{t}$, the difference between a long-term yield and a short-term yield. In the standard consumption-asset pricing framework, asset returns are a function of consumption growth, so following Bakshi and Chen (1994) we include dcons $s_{t}$ as a control variable. This variable is also lagged one year to ensure that it is in the information set at time t. Keim and Stambaugh (1986) and Campbell (1987) find that the term spread is a predictor of risk premiums, so we also include the lagged term spread term $m_{t}$ in $z_{t}$. The term spread also represents the difference in expected intertemporal marginal rates of substitution over long and short horizons (see Harvey 1988). While the literature has found other predictor variables, these cannot be obtained for the very long sample period (almost a century) and for the entire set of countries that we consider.

For hypothesis testing, we compute standard errors using the method in Hodrick (1992), which accounts for both the moving average errors and for heteroskedasticity. Using GMM, the parameters $\theta=\left(\alpha \beta^{\prime}\right)^{\prime}$ in equation (2) have an asymptotic distribution $\sqrt{T}(\widehat{\theta}-\theta) \sim N(0, \Omega)$ where $\Omega=Z_{0}^{-1} S_{0} Z_{0}^{-1}, Z_{0}=\mathrm{E}\left(x_{t} x_{t}^{\prime}\right), x_{t}=\left(1 z_{t}^{\prime}\right)$ and $S_{0}$ is estimated by:

$$
\widehat{S}_{0}=C(0)+\sum_{j=1}^{k-1}\left[C(j)+C(j)^{\prime}\right]
$$

where

$$
C(j)=\frac{1}{T} \sum_{t=j+1}^{T}\left(w_{t+k} w_{t+k-j}^{\prime}\right)
$$

and $w_{t+k}=\epsilon_{t+k, k} x_{t}$. The Hodrick (1992) standard errors exploit covariance stationarity to remove the overlapping nature of error terms in the standard errors computation. Instead of summing $\epsilon_{t+k, k}$ into the future to obtain an estimate of $S_{0}, x_{t} x_{t-j}^{\prime}$ is summed into the past:

$$
\hat{S}_{0}=\frac{1}{T} \sum_{t=k}^{T} w k_{t} w k_{t}^{\prime}
$$

where

$$
w k_{t}=\epsilon_{t+1,1}\left(\sum_{i=0}^{k-1} x_{t-i}\right)
$$


As Ang and Bekaert (2001) and others report, Hodrick (1992) standard errors do not overreject the null of no-predictability, which OLS, Newey-West (1987) and Hansen and Hodrick (1980) t-statistics do. This feature is critical, especially for long horizon studies. Ang (2002) reports that the true size for a Newey-West standard error may be over $40 \%$, when the nominal size is $5 \%$, for long horizons. If we were to use non-Hodrick (1992) standard errors, we would not know if a rejection of the null in favor of predictability would be due to over-rejections of the null hypothesis, or actually reflects a true predictive relationship in line with a given confidence level. The size distortions of Hodrick (1992) standard errors are minimal, ensuring we do not capture spurious predictability relations.

In order to increase power, we pool cross-sectional data across countries. In particular, we estimate a pooled version of regression (2) but impose cross-sectional restrictions, following the method in Ang and Bekaert (2001). In particular, we estimate the equation:

$$
\tilde{y}_{t+k}^{i}=\alpha_{i}+\beta_{i}^{\prime} z_{t}+\epsilon_{i, t+k}
$$

for each country $i$ subject to $\beta_{i}=\bar{\beta}$ across different countries. Under the null hypothesis of constant excess returns, this specification allows each country to have its own individual mean excess return. We pool data by imposing the restriction that the age structure of the population has an impact of the same magnitude on the equity premium in different countries. Appendix B shows how to estimate this system and how to compute Hodrick (1992) standard errors for $\bar{\beta}$.

In the second part of the study, we use monthly data for 15 countries. We place annualized monthly returns over 1, 2 and 5 years horizons on the LHS of equation (2). In this case, $\widetilde{y}_{t+k}=(12 / k)\left(y_{t+1}+\ldots+y_{t+k}\right)$ where $y_{t+1}$ now represent monthly excess returns. Since our demographic data has an annual frequency, we use the population variable in $z_{t}$ which corresponds to the last annual number at the start of the calendar year. (The demographic variables are again lagged by one year to ensure that they are time $t$ measurable). Hence, there are 12 identical observations for $z_{t}, z_{t+1}, \ldots, z_{t+11}$ over the calendar year starting from time $t$. The same exact procedure is applied to annual data on aggregate consumption.

\section{Data}

Our empirical analysis uses two data sets. The first data set spans slightly more than the twentieth century for the US, France, Germany and UK (1900-2001) and from 1920 to 2001 for 
Japan. This data set consists of annual observations on excess aggregate equity returns, several demographic variables, consumption growth and term spread predictors. Section 3.1 describes the US time-series while Section 3.2 compares the US experience with the other G5 countries. In the second data set, we consider a much larger range of countries but a more restricted time period covering the latter third of the last century, 1970 to 2000 . We have monthly observations for the following 15 countries: Australia, Austria, Belgium, Canada, Denmark, France, Germany, Italy, Japan, the Netherlands, Spain, Sweden, Switzerland, the United Kingdom and the United States. One concern about using international data is that since the broad demographic trends are shared by major countries, pooling information across countries may not dramatically increase power. In Section 3.3, we show that since the cross-country variations in changes in demographic growth rates are lowly correlated, pooling data from five countries gives almost the same power as increasing the sample size of the US by five times.

\subsection{Description of Annual US Data}

Figure 1 displays the three US measures of demographic changes we consider: age, the average age of the population over 20, \%age65, the percentage of adult people aged 65 or higher; and \%working, the proportion of the population which is aged [20-64]. We report the levels for these variables in the left column of Figure 1 while the right column shows the continuously compounded annual change of these variables, which are denoted with a " $d$ " prefix. The average age of the adult population is increasing for the whole sample except for the decade 1960-70. The percentage of people over 65 years old rises over the whole last century, although the slope of the graph is lower in the second half of the century. The percentage of the population in the [20-64] working age class increases until the 1950's, then it decreases and starts to rise again after 1970.

These plots all highlight the same phenomenon: the effect of the baby boom generation, a higher than average increase in the birth rate of United States recorded in the period 19501960. The fraction of people in the workforce dropped during those years, because there was a larger number of new babies. In addition, since the average age is calculated using the whole population over 20 years old, the variable dage shows a sharp decline after 1970, exactly when the baby boom generation enters into the calculation of the average. The fraction of adult people over age 65 increases at a lower rate in the last ten years: people from the baby boom generation are not yet retired which implies a larger proportion of the population in the younger age classes. 
Hence, the proportion of the older age class grows at a slower rate. Demographers forecast a reversal of this phenomenon in the very short future when the baby boom generation retires.

The first two columns of Panel A of Table 1 report summary statistics for the US of the demographic variables and asset returns over the full sample. The average age of the US population over the last century is 43 , but the average age has increased from 41 in the first half of the century (1900-1945) to 45 from 1946-2001. The proportion of retired people as a fraction of the adult population averages $12 \%$ across the century, but this has increased on average by nearly 1 percent $(0.89 \%)$ per year. In contrast, the proportion of the working population has stayed at roughly the same level across the century (around 56\%). The levels of the demographic variables age, \%age65 and \%working are highly autocorrelated (over 0.99 in the full sample). On the other hand, the log changes of these variables are more stationary: for example, the autocorrelation of dage is 0.91 in the full sample. ${ }^{5}$

We calculate the excess return ("excess") on the US market as the difference between the continuously compounded total return (price appreciation and dividend return) of the S\&P 500 and the continuously compounded return on a short term risk-free asset. Panel A reports some well known stylized facts on the excess return. US excess returns over the last century are on average $5.22 \%$ and have a volatility of $19.53 \%$ over the whole sample.

The last two rows of Panel A report summary statistics of the two additional regressors we use in our predictive regressions. The first, the US term spread ("term") is calculated as the difference between the long term bond yield and the short term yield. The average term spread is $1.41 \%$ over the entire sample. The second, is the log change in consumption, dcons. Average US consumption growth is around $3.28 \%$ with a volatility of $5.45 \%$.

The US correlation matrix reported in Panel B of Table 1 contains several interesting stylized facts. First, as expected, the demographic variables are correlated with each other: while the correlation is positive between dage and d\%age65 (0.58), the variable d\%working is negatively correlated with both of them (-0.74 and -0.54 respectively). This is because dage and d\%age65 are both measures of population aging and a population with an increasing number of retired people means fewer people in the workforce as a proportion of total population. Second, we confirm that demographic variables are significantly correlated with the risk-free return, as

\footnotetext{
${ }^{5}$ For the US variables age, \%age65 and \%working, we cannot reject the null of a unit root using Dickey-Fuller tests. We also cannot reject the null of a unit root for US dage, d\%age65 and d\%working because of lack of power. However, the dage, d\%age65 and d\%working variables for the other G5 countries are statistically stationary.
} 
Poterba (2001) finds. In contrast, the correlations between the excess returns and the demographic variables are much lower and go in the opposite direction to the correlations with the risk-free rates. Hence, there is some unconditional relation between demographic variables and asset returns in US data.

\subsection{Description of Annual G5 Data}

In Figure 2, we present plots of the demographic variables age, \%age65 and \%working across the US, UK, France, Germany and Japan. While the US, UK, France and Germany share the same broad trends, Japan's experience is quite different. However, even within these broad trends, the demographic experiences of each individual country are also different from each other. We illustrate this with one variable, age, in detail.

In the UK, the average age increases steadily until 1980 and then starts to decrease, possibly due to a high rate of immigration. The pattern in France is less clear: although the trend is increasing, there are several peaks (corresponding to 1921, 1938 [the effect of World War II] and 1966) and downturns (corresponding to 1931, 1939 and 1980). In Germany, the average age of the adult population above 20 years rises at a high rate after World War II, and it starts to slow down during the 1950's. There is a decrease in the 1980's, which may be due to increased foreign immigration. Recently, the average age has started to increase again. In Japan, the average age starts to increase only after 1970. Before this, the age structure of the population is much more stable. After 1970, the increase is quite sharp until the last decade, when the value of the average age stabilizes at a higher level. This observation is consistent, for example, with the fact that only recently has the Japanese government relaxed its immigration policies toward foreign citizens, in particular allowing descendants of Japanese ancestors to emigrate back to Japan.

Panel A of Table 1 lists summary statistics for the G5 countries. Turning first to the demographic variables, the US has a relatively younger population than the UK, Germany, France and Japan. While, on average over the last century, 12\% of the US and the Japanese adult population is above age $65,14 \%$ of the UK and German adult population and $16 \%$ of the French adult population is above retirement age. Compared to the other G5 countries, the US has a fairly fast rate of increase in the demographic variables. The US has a fast average increase $(0.89 \%)$ in the proportion of the adult population over 65 , and only Japan's population has a faster average increase (1.47\%). France's population shows the slowest rate of aging: its means 
of dage, d\%age65 and d\%working are uniformly the lowest across the five countries. Mean excess returns range from $3.02 \%$ for Germany (with a $26.24 \%$ volatility) to $6.89 \%$ in Japan (with a $24.37 \%$ volatility).

Panel $\mathrm{C}$ of Table 1 lists correlation matrices across countries for dage, d\%age65, d\%working and excess. While Figure 2 shows that population levels have broad trends across the G5, Panel $\mathrm{C}$ shows that growth rates in the cross-sectional population are lowly correlated. Hence, the US experiences in population growth rates have not been shared by the UK, Germany, France and Japan. The cross-country correlations for dage, d\%age65 and d\%working are generally low. Japan's dage is generally negatively correlated with the Western countries, but even in Europe the rate of change of the average age is not uniform (the UK-French correlation is close to zero). The US and UK correlation of $d \%$ age 65 is high at $73 \%$, but the correlation of the growth of the fraction of the US population above retirement age is only $8 \%$ with France and is significantly negatively correlated with Japan (-50\%). The cross-country correlations for d\%working have the same signs as those for $d \%$ age 65 and are also fairly low. Turning finally to cross-country correlations of the excess return, the highest cross-country correlation is the US-UK (53\%). The US excess return has only a $25 \%$ and $35 \%$ correlation with France and Germany, and only a $14 \%$ correlation with Japan.

In summary, the demographic experiences of cross-sectional changes and excess return patterns of the G5 countries over the past century are generally lowly correlated. This implies that the time-series data of other countries contain valuable cross-sectional information which we will exploit by cross-sectional pooling. To explicitly show the increase in power by exploiting the cross-country information, we now conduct a simulation exercise to examine the increase in power by using data from foreign countries.

\subsection{Does Adding Cross-Country Data Increase Power?}

Table 1 shows that changes in demographic variables across countries are lowly correlated. We show that this low correlation allows us to increase statistical power by pooling data across countries. To illustrate this, we work with a univariate predictive regression of the form:

$$
y_{t}=\alpha+\beta x_{t-1}+\sigma_{y} u_{t}
$$

for a predictive instrument $x_{t}$ forecasting the variable $y_{t}$ (in our case the excess return) and $u_{t} \sim$ IID N(0,1). To examine power in small samples, we work with the framework of Stambaugh 
(1999), so that $x_{t}$ is an endogenous regressor:

$$
x_{t}=\rho x_{t-1}+\sigma_{x} \epsilon_{t}
$$

where $\epsilon_{t} \sim \operatorname{IID~N}(0,1)$.

Our strategy is as follows. We use the data-generating process (DGP) of (8) and (9) to simulate out data from one country (the US), of 99 years, the same length as our G5 one-period ahead regression sample. We simulate out under the alternative that $\beta \neq 0$, and re-estimate the predictive regression (8) (which corresponds to (2) with $k=1$ ) in the small sample and record the Hodrick (1992) t-statistic. Using critical values corresponding to $10 \%$ and $5 \%$ nominal size levels (for two-sided tests), we record the proportion of rejections of the null hypothesis. Our goal is to see the improvement in power by increasing the US sample to $2 \times 99,3 \times 99$, $4 \times 99$ and $5 \times 99$ years. We compare this to the power of pooling the data from $2,3,4$ and 5 'average' countries, which are correlated with the US sample. The pooled regression (7) data is re-estimated in each simulated sample, where each country has a sample length of 99.

Our calibrated values for the DGP are determined as follows. We set $\rho=0.94$, from the autocorrelation of d\%age65 for the US, $\sigma_{x}=0.0024$ giving $x_{t}$ an unconditional volatility of 0.007 , as in US data. We conduct our power analysis under the null hypothesis that $\beta=0$ and under the alternative hypothesis that $\beta=-2.1$, which is the empirical value of the regression (detailed in Section 4). We set $\sigma_{y}=0.23$, which is the average volatility of the G5 excess returns, slightly higher than the volatility of the US excess return (0.20). Panel B of Table 1 shows the unconditional correlation in the US of excess returns and d\%age65 is 0.05 , which we set as the correlation of $u_{t}$ and $\epsilon_{t}$ under the null. In Panel $\mathrm{C}$ of Table 1, the average cross-country correlation of US d\%age65 and d\%age65 in other countries is 0.38, excluding Japan, and we set the correlation of US shocks to d\%age65 and shocks to foreign excess returns at zero.

Table 2 lists the results of the small sample power analysis. First, power is fairly low, with power being only $17.29 \%(10.59 \%)$ for a $10 \%(5 \%)$ nominal size level for using only US data. This is because the volatility of excess returns is very high, $23 \%$, relative to the variation caused by the predictable components due to demographic variables. Hence, trying to pick up demographic predictability of risk premiums is very difficult even with samples of a century of data without pooling or further increasing the data sample. Second, power naturally increases as the data sample for the US is increased from 99 years to 495 years. Increasing the data sample of a single country by a factor of five increases power to $45.75 \%(33.45 \%)$ at a $10 \%$ (5\%) nominal size level. 
Third, we see that the increases in power for using pooled cross-country information is almost the same for increasing the sample length of the US. For example, at a 5\% level, using data from three countries produces a power of $21.15 \%$ which is almost exactly the same power as increasing the data sample of the US alone by three times $(21.38 \%)$. For five countries, the power corresponding to a size level of $5 \%$ is $31.46 \%$, only slightly less than increasing the US data sample by a factor of five $(33.45 \%)$. Power from using cross-country information is lower than simply increasing the US data sample because the demographic information across countries is correlated. However, the loss in power from using cross-country information is almost negligible, compared to increasing the US data sample, because the correlations of demographic changes across countries are low (see Panel $\mathrm{C}$ of Table 1). In summary, cross-country pooling is a very good way to increase power for examining the relationship between demographic variables and excess returns.

\section{Empirical Results}

\subsection{Demographic Predictability in the US}

Table 3 reports the results of the regression in equation (2) for the US over the full sample 1900-2001. We present forecast horizons of the excess return over 1 year, 2 years and 5 years. For each horizon, we list the results of univariate regressions of changes of each demographic variable dage, d\%age65 and d\%working. We include the two predictors dcons and term as control variables in trivariate regressions with each demographic variable.

Table 3 shows very weak predictability, generally not even significant at the $10 \%$ level, for the risk premium by any demographic variable. In one sense, this is consistent with many theoretical studies who find only weak relationships between demographic effects and risk premiums. The point estimates show that a 1 basis point increase in the average adult age increases the risk premium by 16 basis points at a 1-year horizon. Controlling for $d$ cons and term, d\%age65 is significant at the $10 \%$ level at a 1-year horizon but produces an $R^{2}$ of only $3.90 \%$. The point estimates are consistent with Bakshi and Chen (1994), and other US studies, who find that a change in the average age is positively related to future risk premiums. However, with robust standard errors and a larger sample period, our predictability evidence is weak. We now check the robustness of the relationship between population changes and risk premiums with 
international data.

\subsection{Demographic Predictability Across the G5 Countries}

The regression results over the full sample are reported in Tables 4 and 5 for the UK and Japan. We comment (but do not report) on the regression results for France and Germany below. Table 6 reports results of a joint regression estimated cross-sectionally across all G5 countries.

We turn first to the UK in Table 4. For a 1-year horizon, the point estimates of the coefficients of dage, d\%age65 and d\%working have the same sign as the US. However, the UK dage coefficient is one order of magnitude less than the US and becomes negative over longer forecast horizons. Like the US results, d\%working is not a significant predictor at any horizon. The demographic variable which does have significant predictive power for excess returns is d\%age65, which is positive and significant over all horizons (significant at the $1 \%(5 \%)$ level for a 1-year (2-year and 5-year) horizon). In particular, a 1\% change in d\%age65 increases the equity premium by around 3-4\% at all horizons. These are almost the same point estimates as for the US, except that the US point estimates are all insignificant across all horizons. The change in the proportion of retired persons also retains its significance controlling for dcons and term in the trivariate regression.

Table 5 reports the results of the predictive regressions for Japan, which are run over the period 1920-2001. The demographic coefficients are all significant at the 1-year horizon, but are exactly the opposite sign to the US regressions. For the 1-year horizon in the univariate regressions, dage, d\%age65 and d\%working are all significant at the 5\% level. However, controlling for dcons and term, the predictability of each of these demographic variables diminishes so that the only significant predictor controlling for these instruments is d\%age65. At 2-year and 5-year horizons, no demographic variable is a significant predictor.

For the regressions for France and Germany, there is no evidence of predictability at the $5 \%$ level, but some predictability at the $10 \%$ level. We might have expected that France and Germany would give similar results as the US. However, this is not the case. For short horizons, the point estimates of the demographic for France and Germany have the same sign as Japan, which is exactly opposite to the US coefficients. Overall, this suggests that any relation between expected returns and demographic variables may be different in international data to the US experience.

The first conclusion to draw from these results is that demographic variables do predict 
excess returns in international data, at least in the UK and Japan. This evidence is much stronger than US data. Second, the demographic variable which other authors have found to predict excess returns in the US (change in the average age of the population with a positive sign) is not a result that extends to other countries. In other countries d\%age65 is the best demographic predictor of excess returns, and it is highly significant. Third, the sign of the coefficients on the demographic instruments are different in the US than from other countries. The variable d\%age65 predicts excess returns in some countries with the same sign as the US (the UK) or with the opposite sign to the US (France and Germany). Japan has exactly the opposite results of demographic predictability of risk premiums to the US.

To increase the power of the tests, we pool data across all G5 countries and estimate equation (7) constraining the demographic variables to have the same coefficients in each country, but allow each country to have different constant excess returns under the null of no predictability. We introduce a dummy variable to account for the years of the World Wars, where data points are missing for several countries. Our sample period is 1920-2001, since the Japanese data starts in 1920.

Table 6 reports the results of the pooled regression across the G5 countries. In the regressions at the 1-year horizon, both dage and d\%age65 have negative coefficients. These results are the opposite to those obtained estimating only with US data. The variable d\%working has a negative sign at short horizons, but turns positive at long horizons. Across all horizons, only the Hodrick (1992) t-statistic of d\%age65 is significant at a 5\% level in the regressions controlling for dcons and term. The d\%age65 coefficient increases its significance to the $1 \%$ level at the 5-year horizon. In particular, at a 1-year (5-year) horizon, for a 1\% increase in the percentage of the adult population which is retired, the risk premium is forecasted to decrease by $2.12 \%$ $(1.34 \%)$, controlling for the effects of predictability by consumption growth and term spreads.

The pattern of increases in $d \%$ age 65 driving reductions in the risk premium is largely due to the relationship between excess returns and the ageing of the populations in France, Germany and Japan. In these countries, it is d\%age65 which has most predictive power, with a negative sign, rather than positive sign as in the US regression. Hence, while demographic predictability in the US is very weak, it is much stronger in international data. Furthermore, the weak positive correlation between excess returns and the average age of population in the US is not a robust empirical phenomenon which other countries share. Across the G5 countries, it is the change of the fraction of retired people which has most predictive power for excess returns, with a 
negative sign.

\subsection{Demographic Predictability Across Fifteen Countries}

Figure 3 shows the coefficients of the demographic variables with $95 \%$ confidence bounds from trivariate regressions over the 1-year forecast horizon. In each regression we control for $d$ cons and term using monthly data. Each country is abbreviated by a code in the $x$-axis. Panel A shows the coefficients of dage, where every country except Spain and the US has insignificant coefficients. The US coefficient is roughly twice the magnitude across this shorter 30-year subsample, as over the full century, and is now significant at the $5 \%$ level. This is a much stronger result than over the full century in Table 3.

Panel B shows the coefficient $d \%$ age65. In contrast to the full sample, the point estimate of the US coefficient is negative, although the standard error is very large. With the exception of the UK, every country has negative point estimates. Italy and Spain are significantly negative at the 5\% level, but many countries, including Australia, Austria, Denmark, France, Germany, and Sweden are significantly negative at the $10 \%$ level. Panel C of Figure 3 shows the regression coefficients of $d \%$ working. Most countries have positive coefficients, many of them significant, while the US has a significantly negative coefficient.

Table 7 reports pooled cross-country regression results for the fifteen countries. The coefficients for d\%age65 and d\%working have the same sign as the joint regressions over the G5 countries in Table 6. The most significant demographic variable for the US, dage, is not significant at any horizon, but the positive sign is the same as in the US regressions. However, the pooled country estimation over 15 countries supports the hypothesis that there is a negative correlation between the growth in the fraction of the adult population over 65 years old and future excess equity returns.

In Table $7, d \%$ age 65 is significant at the $1 \%$ level in univariate regressions for all horizons, and controlling for dcons and term, d\%age65 remains significant at the $1 \%$ level across all horizons. Looking at the point estimates, at a 1-year horizon, increasing the growth of the fraction of the adult population over 65 by $1 \%$ decreases the equity premium by $4.11 \%(2.31 \%)$ at a 1-year (5-year) horizon, controlling for dcons and term. Turning finally to d\%working, this variable is also not significant at the $5 \%$ level over any horizon, controlling for consumption growth and the term spread. The positive signs on d\%working are the opposite of the US coefficients. 
Hence, the results of a much larger sample confirm that the US experience with demographic change and excess returns does not conform to international experience. While demographic variables significantly predict excess returns, the US demographic variables are not the same variables which predict excess returns internationally, nor do they even predict with the same sign. Internationally, increases in the proportion of retired people decrease risk premiums.

\section{Demography, Social Security and Market Development}

There may be several reasons why the US risk premium predictability by demographic variables is different from the experiences of other countries. First, structural differences among the financial system of the United States and other developed countries might partly explain the differences in the results. For example, as shown in Constantinides, Donaldson and Mehra (2002), the presence or absence of the young as financial market participants substantially influences equilibrium security returns. The degree of participation in the equity market and the ability to borrow against human capital may be quite different across the countries considered in the sample. Second, the US generally has lower social security benefits and a much more established equity culture than other countries. The existence of "more generous" social security systems may also affect portfolio allocation between risky and riskless assets.

In this section, we examine if the demographic predictability of the risk premium differs across countries due to differences in social security systems and the relative degree of the development of financial markets. We use the same technique of pooled cross-country regressions, but divide our group of countries into two subgroups, depending on the institutional characteristics of each country. Our motivation here is to further examine which characteristics of the countries are behind the strong predictability of excess returns by demographic changes.

\subsection{Social Security Benefits}

In international data, we find that the greater the change in the proportion of people over 65 , the lower the risk premium, both for the G5, and for the larger sample of 15 developed countries. For this age class, as well as middle-aged investors saving for retirement, investment choices are likely to be affected by the amount of social security benefits that households receive during retirement and by the expected variability of these benefits, as perceived when investors are middle-aged. To see if cross-country differences in social security affect the relationship 
between demography and expected returns, we divide countries into two groups, depending on how "socially developed" the country is.

We construct an indicator of "social security development" using data from the OECD Social Expenditure Database. This indicator captures the percentage of public expenditures which represents benefits for retired people. These benefits are the sum of "old age cash benefits" and "services for the elderly and the disabled." The indicator of Social Security benefits is constructed as follows:

$$
I_{S S}=\frac{(\text { old age cash benefit })+(\text { services for the elderly and the disabled })}{(\text { total public expenditures }) \times(\text { percentage of people over } 65)} .
$$

The indicator is divided by the percentage of people over 65 in order to correct for the size of the "old population." This value is greater than one for most of the countries we consider, which implies that the percentage of social expenses directed to the old population is higher than the percentage of people over 65. The fifteen countries are then divided in two groups, split according to the median value of the averages of (10) for each country. Panel A of Table 8 lists the two groups. The groups are as expected, with Switzerland and Italy appearing as the two countries with the highest level of social security benefits, except that Canada and Sweden appear as the countries with the least benefits. This might be due to the fact that in the OECD data, health benefits paid cannot be separated into benefits paid only for old people, so Canada and Sweden are most likely severely under-ranked. ${ }^{6}$ Nevertheless, the ranking provides a firstcut look at the generosity of social security benefits.

Panel B of Table 8 reports the results of the two pooled cross-country regressions. We report only the demographic coefficient in the trivariate regression (and omit the coefficients on dcons and term). The most interesting result is that d\%age65 is a significant predictor, with a negative sign, for both groups of countries at all horizons. However, d\%age65 is a more significant predictor, with larger magnitudes of the point estimates of the regression coefficients, for high benefit countries than for low benefit countries. This result is intuitive: in countries with low social security benefits, retirees are forced to dis-save some of their wealth to fund their consumption, and the demographic predictability of $d \%$ age65 is muted. In contrast, in countries with high social security benefits, old people participate in financial markets not to

\footnotetext{
${ }^{6}$ A second indicator adds health $\times$ (percentage of people over 65) to the numerator in (10). The regression results obtained including health expenses are very similar to the results obtained when health expenses are excluded in (10).
} 
sell securities to fund their retirement, but may save for other purposes like bequest motives and pure speculation, and hence may more directly affect equity premiums.

\subsection{Financial Market Development}

The relative importance of financial markets compared with the "real" side of the economy is different across countries. This in turn is likely to affect households' equity participation, as argued, for example, by Ameriks and Zeldes (2001). To examine the effect of financial market development on the demographic predictability of excess returns, we divide the countries into two subgroups, according to the value of a "market development" indicator. This indicator is calculated as follows:

$$
I_{M D}=\frac{\text { GDP }(\text { US\$) }}{(\text { domestic market capitalization (US\$)) }}
$$

for each country. The larger the value of the indicator, the less important is the financial market compared with the real economy. Panel A of Table 9 reports the average values of this indicator for the fifteen countries. The sample of countries is split in two subgroups, according to the median value. At the top of the list is Switzerland. The country with the smallest traded financial markets relative to the size of its economy is Austria.

Panel B of Table 9 lists the results of the cross-country pooled regressions. For countries with a low level of market development, d\%age65 is extremely significant across all horizons, with a negative coefficient. In contrast, for countries with highly developed financial markets, the point estimates of the d\%age65 coefficient are smaller $(-5.31(-2.88)$ for the low (high) market development countries) and are generally less significant. At the 1-year horizon, low market development countries are highly significant at less than the $1 \%$ level $(\mathrm{t}$-stat $=-5.09)$, while high market development countries are significant only at the 5\% level $(\mathrm{t}$-stat $=-2.17)$. Note that the pooling according to social security benefits and market development differ only for two countries. ${ }^{7}$ Hence, countries characterized by higher social security benefits tend also to have less-developed financial systems.

Countries with less-developed financial markets are likely to have less liquid, smaller markets with low stock market participatio different from the US experience (see Guiso, Haliassos

\footnotetext{
${ }^{7}$ Specifically, Japan and Switzerland belong to Group 1 in the market development pooling, while they were part of Group 2 in the social development pooling. Consequently, Belgium and Denmark belong to Group 2 for the market-development pooling and to Group 1 for the social development one.
} 
and Jappelli 2000). (Note that the three largest stock markets, the US, Japan and the UK all belong to the high market development group.) Hence, in countries with less-developed financial systems, the segment of the population holding relatively large amounts of stocks, in particular old people, are more likely to have a larger influence on stock prices. In these countries, if the elderly seek to own stocks, aging populations will likely result in an increasing proportion of retirees bidding up stock prices, and subsequently decreasing risk premiums.

\section{Conclusions}

We investigate the link between demographic changes and excess returns in the largest five developed markets over most of the twentieth century, and in a larger sample of 15 countries over the last third of the twentieth century. We pool this cross-sectional data allowing for more efficient estimation and more powerful tests, and conduct inference of short and long horizon predictability with robust Hodrick (1992) standard errors.

Our results have several implications for the development of theoretical models. First, existing Overlapping Generations (OLG) models predict that shifts in age distributions of the population do change the relative pricing of financial assets, even when these demographic changes are rationally anticipated. We find strong empirical evidence that demographic changes predict future excess returns in international data, but the US evidence is very weak.

However, the theoretical OLG models in the literature are usually calibrated only to past US demographic changes, which we find is lowly correlated with international demographic experience. Hence, other countries provide additional cross-sectional data to test if demographic changes predict excess returns. Moreover, the changes of demographic variables in other countries is lowly correlated with the US and the degree of stock market participation in some other countries is also quite different to US experience. Testing the predictions of theoretical models internationally is also important to check their robustness.

The demographic variables that predict US excess returns are not the same demographic variables that predict excess returns on other countries. We confirm previous studies using US data that changes in the average age of the population weakly predict US excess returns. However, this variable has no predictive power for excess returns internationally. The most powerful predictive demographic variable for international excess returns is the change in the proportion of retired people, as a fraction of the adult population. A growing proportion of retired 
people significantly forecasts decreases in the equity premium, over 1,2 and 5 year forecasting horizons. Our international empirical results back up the predictions of Abel (2001b and 2003), who suggests that as the baby boom generation enters retirement, and leaves the middleage peak-saving years, future realized excess returns on equity will be low. This demographic predictability of risk premiums by changes in the proportion of retirees is strongest for countries with high levels of social security benefits and for countries with less-developed financial systems. 


\section{A Data Appendix}

Financial data on stocks and interest rates for the annual database are provided by Global Financial Data (GFD). Whenever possible we indicate the way the historical series has been constructed by GFD. Population data from 1900 to 1949 are from Mitchell (MI) (1992). From 1950 on, population data are from Eurostat (EU). Annual aggregate consumption is estimated as the difference between the total value of the real GDP and the share of GDP that is invested. Data on GDP, Savings and Investments are from various sources: the World Bank (WB), Jones and Obstfeld (JO) (1997), Bordo and Jonung (BJ) (1987), Taylor (TR) (1999) and (MI).

\section{Annual Data}

Annual excess returns are calculated as the difference between the total return (price index plus dividend return) on the local equity index and the total return on a short term "risk-free" investment. Data on total returns are provided by GFD, which combine both current indices that are calculated by national stock exchanges since the 1980's and recalculated indices based on historical data for dividend yields and price appreciation before their publication by the national stock exchanges.

United States: Equity returns represent price plus dividend returns (total returns) from GFD, which are compiled from the S\&P 500. Risk-free returns are total returns from GFD, calculated from Commercial Bills prior to 1935 and from 3-month T-Bills thereafter. Long-term and short-term yields are from GFD. The long-term yield is the yield on the 30 year Government Bond, the short-term yield is the yield on a Commercial Bill until 1914, the discount rate from 1915 to 1930 and the yield on a 3-month T-Bill thereafter. Population data are from the U.S. Census Bureau, "Statistical Abstract of the United States", various years. The real GDP is from JO until 1939, BJ until 1959 and WB thereafter. For the investment share of GDP we use JO until 1945, TR until 1964 and the WB thereafter.

United Kingdom: Equity returns represent price plus dividend returns (total returns) from GFD, which are compiled from the FTSE All-Share Index. Risk-free returns are total returns on a 3-month Government Bill, from GFD. Long-term and short-term bond yields are provided by GFD. The long-term yield is the yield of a Consol Bond, while the short-term yield is computed from a 3-month T-Bill. Population data come from MI from 1900 to 1949 and EU from 1950 to 1998. The real GDP is from JO until 1939, BJ until 1959 and WB thereafter. For the investment share of GDP we use JO until 1945, TR (1999) until 1964 and the WB thereafter.

France: Equity returns represent price plus dividend returns (total returns) from GFD, which are constructed by replicating the MSCI index for all the last century. Risk-free returns are discount rates from 1900 to 1929 and total returns on a 3-month T-Bill thereafter, from GFD. Long-term and short-term yields are provided by GFD. The long-term yield is the yield of a 10-year Government Bond, while the short-term yield is the discount rate from 1900 to 1930 and the yield of a 3-month T-Bill thereafter. Population data are from MI from 1900 to 1949 and EU from 1950 to 1998. For the real GDP we use JO until 1979, BJ for missing years and WB from 1960 on. For the investment share of GDP we use JO until 1945, MI until 1966 and WB from 1967. The years from 1914 to 1920 and from 1939 to 1948 are excluded from the multivariate regressions because of missing data on aggregate consumption.

Germany: Equity returns represent price plus dividend returns (total returns) from GFD, which are compiled from the CDAX Composite index. Risk-free returns are discount rates from 1900 to 1919, total returns on 3-month Private Bills until 1952 and total returns on 3-month Government Bill thereafter. Long-term and short-term yields are provided by GFD. The long-term yield is an average of yields for all $8-15$ year bonds, which is an index reported by the Bundesbank. The short-term yield is the discount rate from 1900 to 1952 and the yield of a 3-month T-Bill thereafter. Population data are from MI from 1900 to 1949 and from Myers and Mauldin (1952) for the years 1939-1945. Population statistics from 1950 
to 1998 are provided by EU. For real GDP we use MI until 1959, WB from 1960 on. For the investment share of GDP we use JO until 1945, TR from 1946 to 1966, WB from 1967. In the univariate regressions, the years from 1914 to 1925 are excluded from the sample because of missing data for equity returns. In the multivariate regressions, the years from 1939 to 1949 are excluded because of missing consumption data.

Japan: Equity returns represent price plus dividend returns (total returns) from GFD, which are compiled from the NIKKEI Securities index. Risk-free returns are total returns on 3-month Private Bill until 1959 and total returns on 3-month Government Bill thereafter. Long-term and short-term yields are provided by GFD. The long-term yield is the yield of a 7-year Government Bond, while the short-term yield is the discount rate from 1900 to 1959 and the yield of a 3-month T-Bill thereafter. Population data are from "Japan Statistical Yearbook: 1996" from 1920 to 1996 and from the United Nations Annuary thereafter. For the real GDP we use JO until 1939, BJ until 1959 and WB thereafter. For the investment share of GDP we use JO until 1945, TR until 1964 and WB thereafter.

\section{Monthly data}

Excess returns are calculated as the difference between the total return on the local MSCI total return index and the domestic discount rate. Monthly data on discount rates are from "International Financial Statistics" (IFS) published monthly by the International Monetary Fund (IMF) Statistics Department, except data on Swedish discount rates that were provided by the Central Bank of Sweden. Monthly yields on long-term bonds are from IFS, following the IMF classification for long-term bonds. Annual consumption is Private Consumption Expenditures from the country table of the publication "Main Economic Indicators" of the OECD. For the G5 countries, population data are from the same sources as the annual data. For all the other European countries population data are from EU. For all the remaining countries, population data are from the "Demographic Yearbook" published by the United Nations. The value for the monthly change in consumption and population is the one year continuously compounded change repeated for 12 months over the calendar year.

\section{Social Development and Market Development Indicators}

Data on social expenses are from the OECD Social Expenditure Database (1999). The database contains social indicators from 1980 to 1997. Data on market capitalisation are from the World Federation of Stock Exchanges from 1975 to 1998, in US dollars. GDP values are from the OECD database and they refer to GDP in US dollars (series in local currency have been converted using the exchange converter of the OECD), calculated at market prices, in nominal terms.

\section{B Estimating the Pooled Regression and Deriving Hodrick (1992) Standard Errors}

We want to estimate the system:

$$
\tilde{y}_{t+k}^{i}=\alpha_{i}+\beta_{i}^{\prime} z_{t}^{i}+u_{t+k, k}^{i}
$$

for $i=1 \ldots N$ countries subject to the restriction that:

$$
\beta_{i}=\bar{\beta} \quad \forall i .
$$

There are $K-1$ factors in $z_{t}^{i}$. In this Appendix, we derive Hodrick (1992) standard errors for the estimate of $\bar{\beta}$. This derivation is based on Ang and Bekaert (2001). 
Denote the free parameters $\theta=\left(\alpha_{1} \ldots \alpha_{N} \bar{\beta}^{\prime}\right)^{\prime}$, and the unrestricted parameters stacked by each equation $\beta=\left(\alpha_{1} \beta_{1}^{\prime} \ldots \alpha_{N} \beta_{N}^{\prime}\right)^{\prime}$. We can estimate the system in equation (B-1) subject to the restriction that $C \beta=0$, where $\mathrm{C}$ is a $N K \times(N-1)(K-1)$ matrix of the form:

$$
C=\left(\begin{array}{ccccccccc}
\tilde{0} & I & \tilde{0} & -I & \tilde{0} & \ldots & & & \\
\tilde{0} & O & \tilde{0} & I & \tilde{0} & -I & \ldots & & \\
\vdots & & & & & & & & \\
\tilde{0} & O & \tilde{0} & \ldots & & & & \tilde{0} & -I
\end{array}\right)
$$

where $\tilde{0}$ is a $(K-1) \times 1$ vector of zeros, $O$ is a $(K-1) \times(K-1)$ matrix of zeros, and $I$ is a $(K-1)$ rank identity matrix.

Denote:

$$
\begin{array}{lr}
\tilde{y}_{t+k}=\left(\tilde{y}_{t+k}^{1} \ldots \tilde{y}_{t+k}^{N}\right)^{\prime} & (N \times 1) \\
x_{t}^{i}=\left(1 z_{t}^{i^{\prime}}\right) & (K \times 1) \\
u_{t+k}=\left(u_{t+k, k}^{1} \ldots u_{t+k, k}^{N}\right)^{\prime} & (N K \times 1) \\
X_{t}=\left(\begin{array}{ccc}
x_{t}^{1} & 0 \\
& \ddots & \\
0 & & x_{t}^{N}
\end{array}\right) &
\end{array}
$$

Using this notation, the system can be written as:

$$
\tilde{y}_{t+k}=X_{t}^{\prime} \beta+u_{t+k, k}
$$

subject to $C \beta=0$. To write in compact notation let $Y=\left(\tilde{y}_{1+k}^{\prime} \ldots \tilde{y}_{T+k}^{\prime}\right)^{\prime}, X=\left(X_{1}^{\prime} \ldots X_{T}\right)^{\prime}, U=$ $\left(u_{1+k, k}^{\prime} \cdots u_{T+k, k}^{\prime}\right)^{\prime}$. Then the corresponding compact system to (B-5) is:

$$
Y=X \beta+U \quad \text { subject to } C \beta=0 .
$$

A consistent estimate $\hat{\beta}$ of $\beta$ is given by:

$$
\hat{\beta}=\beta^{\text {ols }}-\left(X^{\prime} X\right)^{-1} C^{\prime}\left[C\left(X^{\prime} X\right)^{-1} C^{\prime}\right]^{-1} C \beta^{o l s},
$$

with $\beta^{\text {ols }}=\left(X^{\prime} X\right)^{-1} X^{\prime} Y$. This gives us an estimate $\hat{\theta}$ of $\theta$.

To derive Hodrick (1992) standard errors, we set up the moment conditions of the system in equation (B-5):

$$
\mathrm{E}\left(h_{t+k}\right)=\mathrm{E}\left(X_{t} u_{t+k, k}\right)=0 .
$$

By standard GMM, $\hat{\theta}$ has distribution:

$$
\sqrt{T}(\hat{\theta}-\theta) \stackrel{a}{\sim} N\left(0,\left(D_{0}^{\prime} S_{0}^{-1} D_{0}\right)^{-1}\right),
$$

where:

$$
D_{0}^{\prime}=\mathrm{E}\left[\frac{\partial h_{t+k}}{\partial \theta^{\prime}}\right]
$$

and

$$
S_{0}=\mathrm{E}\left(h_{t+k} h_{t+k}^{\prime}\right)
$$

The Hodrick (1992) estimate $\hat{S}_{T}^{b}$ of $S_{0}$ is given by:

$$
\hat{S}_{T}^{b}=\frac{1}{T} \sum_{t=k}^{T} w k_{t} w k_{t}^{\prime}
$$


where $w k_{t}(N K \times 1)$ is given by:

$$
w k_{t}=\left(\sum_{i=0}^{k-1} X_{t-i}\right) e_{t+1} .
$$

Under the null hypothesis of no predictability $u_{t+k, k}=e_{t+1}+\ldots e_{t+k}$ where $e_{t+1}$ are the 1-step ahead serially uncorrelated errors. This is the SUR extension of the estimate given in Hodrick (1992).

A consistent estimate $\hat{D}_{T}$ of $D_{0}$ is given by:

$$
\hat{D}_{T}^{\prime}=\frac{1}{T} \sum_{t=0}^{T} \frac{\partial h_{t+k}}{\partial \theta^{\prime}},
$$

$\theta=\left(\alpha_{1} \ldots \alpha_{N} \bar{\beta}^{\prime}\right)$ with

$$
-\frac{\partial h_{t+k}}{\partial \theta^{\prime}}=\left[\begin{array}{cccccccc}
1 & z_{t}^{1^{\prime}} & & & & 0 & \\
& & 1 & z_{t}^{2^{\prime}} & & & \\
& & & & \ddots & & \\
& & 0 & & & 1 & z_{t}^{N^{\prime}} \\
z_{t}^{1} & z_{t}^{1} z_{t}^{1^{\prime}} & z_{t}^{2} & z_{t}^{2} z_{t}^{2^{\prime}} & \ldots & z_{t}^{N} & z_{t}^{N} z_{t}^{N^{\prime}}
\end{array}\right]
$$

Hence, the estimate $\hat{\theta}$ has an asymptotic distribution:

$$
\sqrt{T}(\hat{\theta}-\theta) \stackrel{a}{\sim} N\left(0,\left[\hat{D}_{T}^{\prime}\left(\hat{S}_{T}^{b}\right)^{-1} \hat{D}_{T}\right]^{-1}\right) .
$$




\section{References}

[1] Abel, A. B. 2001a. The social security trust fund, the riskless interest rate and capital accumulation. In J. Campbell and M. Feldstein (eds.), Risk Aspects of Investment-Based Social Security Reform, pp. 153-193. Chicago: University of Chicago Press.

[2] Abel, A. B. 2001b. Will bequests attenuate the predicted meltdown in stock prices when baby boomers retire? Review of Economic and and Statistics 83 (November): 589-595.

[3] Abel, A. B. 2003. The effects of a baby boom on stock prices and capital accumulation in the presence of social security. Econometrica (forthcoming).

[4] Allen, F., and Gale, D. 1994. Limited market participation and volatility of asset prices. American Economic Review, 84 (September): 933-55.

[5] Ameriks, J., and Zeldes, S. P. 2001. How do household portfolio shares vary with age? Working paper. New York: Columbia Business School.

[6] Ang. A. 2002. Characterizing the ability of dividend yields to predict future dividends in log-linear present value models. Working paper. New York: Columbia Business School.

[7] Ang, A., and Bekaert, G. 2001. Stock return predictability: Is it there? Working paper. New York: Columbia Business School.

[8] Bakshi, G. S., and Chen, Z. 1994. Baby boom, population aging and capital markets. Journal of Business 67 (April): 165-202.

[9] Bergantino, S. M. 1998. Lifecycle investment behavior, demographics and asset prices. Unpublished doctoral dissertation. Boston, Mass.: MIT.

[10] Bordo, M., and Jonung, L. 1987. The Long-Run Behaviour of the Velocity of Circulation: The International Evidence. New York: Cambridge University Press.

[11] Brooks, R. J. 1998. Asset market and saving effects of demographic transitions. Unpublished doctoral dissertation. New Haven, Conn.: Yale University.

[12] Brooks, R. J. 2002a. Asset market effects of the baby boom and social security reforms. American Economic Review Papers and Proceedings 92 (June): 402-406.

[13] Brooks, R. J. 2002b. The equity premium and the baby boom. Working paper. Washington, D.C.: International Monetary Fund.

[14] Campbell, J. Y. 1987. Stock returns and the term structure. Journal of Financial Economics 18 (June): 37399.

[15] Campbell, J. Y., Cocco, J. F., Gomes, F. J., and Maenhout, P. J. 2001. Investing retirement wealth: A lifecycle model. In J. Campbell and M. Feldstein (eds.), Risk Aspects of Investment-Based Social Security Reform, pp. 439-473. Chicago: University of Chicago Press.

[16] Constantinides, G., Donaldson, J. B., and Mehra, R. 2002. Junior can't borrow: A new Perspective on the equity premium puzzle. Quarterly Journal of Economics 117 (February): 269-96.

[17] Constantinides, G., and Duffie, D. 1996. Asset pricing with heterogeneous consumers. Journal of Political Economy 104 (April): 219-240.

[18] Davis, E. P., and Li, C. 2002. Demographic and financial asset prices in the major industrial economies. Working paper. London, U.K.: Brunel University.

[19] Donaldson, J. B., and Maddaloni, A. 2002. The impact of demographics differences on asset pricing in an equilibrium model. Working paper. New York, N.Y.: Columbia Business School.

[20] Erb, C. B., Harvey, C. R., and Viskanta, T. E. 1997. Demographics and international investments. Financial Analysts Journal 53 (July/August): 14-28. 
[21] Goyal, A. 2002. Demographics, stock market flows and stock returns. Journal of Financial and Quantitative Analysis (forthcoming).

[22] Guiso, L., Haliassos M., and Jappelli, T. 2000. Household portfolios: An international comparison. Working Paper no. 48. Salerno, Italy: University of Salerno, Centre for Studies in Economics and Finance (CSEF).

[23] Harvey, C. R., 1988. The real term structure and consumption growth. Journal of Financial Economics 22 (December): 305-334.

[24] Hansen, L., and Hodrick, R. J. 1980. Forward exchange rates as optimal predictors of future spot rates: An econometric analysis. Journal of Political Economy 88 (October): 829-853.

[25] Hodrick, R. J., 1992. Dividends yields and expected stock returns: Alternative procedures for inference and measurement. Review of Financial Studies 5 (Fall): 357-386.

[26] Jones, M., and Obstfeld, M. 1997. Saving, investment and gold: A reassessment of historical current account data. Working paper no. 6103. Cambridge, Mass.: National Bureau of Economic Research.

[27] Keim, D., and Stambaugh, R. F. 1986. Predicting returns in the stock and bond markets. Journal of Financial Economics, 17 (December): 357-390.

[28] Lampman, R. 1962. Share of Top Wealth Holders in National Wealth: 1922-1956. Princeton, N.J.: Princeton University Press.

[29] Luo, J., 2000. Demographics and the equity premium. Unpublished doctoral dissertation. Los Angeles, Cal.: UCLA.

[30] Mankiw, N. G., and Weil, D. N. 1989. The baby boom, the baby bust, and the housing market. Regional Science and Urban Economics 19 (May): 235-258.

[31] Mitchell, B. R. 1992. International Historical Statistics: Europe 1750-1988. New York: Stockton Press.

[32] Myers, P. F., and Mauldin, W. P. 1952. Population of the Federal Republic of Germany and West Berlin. International Population Statistics Reports. Washington, D.C.: Bureau of the Census, US Government Printing office.

[33] Newey, W. K., and West, K. D. 1987. A simple positive semi-definite, heteroskedasticity and autocorrelation consistent covariance matrix. Econometrica 55 (May): 703-8.

[34] Poterba, J. M. 2001. Demographic structure and asset returns. Review of Economics and Statistics 83 (November): 565-584

[35] Statistics Bureau, Management and Coordination Agency, 1997. Japan Statistical Yearbook 1996. Tokyo, Japan: Japan Statistical Association.

[36] Stambaugh, R. F. 1999. Predictive regressions. Journal of Financial Economics 54 (December): $375-421$.

[37] Storesletten, K., Telmer, C., and Yaron, A. 2001. Asset pricing with idiosyncratic risk and overlapping generations. Working paper. Pittsburgh, Penn.: Carnegie Mellon University.

[38] Taylor, A. M. 1999. Sources of convergence in the late nineteenth century. European Economic Review 43 (October): 1621-45.

[39] Tesar, L. L., and Werner, I. M. 1995. Home bias and high turnover. Journal of International Money and Finance 14 (August): 467-493.

[40] United Nations, several years, Demographic Yearbook, New York: United Nations Publications.

[41] US Census Bureau, several years, Statistical Abstract of the United States, Washington, D.C.

[42] Yoo, P. S. 1994a. Age dependent portfolio selection. Working paper no. 94-003A. St. Louis, Miss.: Federal Reserve Bank of St. Louis.

[43] Yoo, P. S. 1994b. Age distributions and returns on financial assets. Working paper no. 94-002B. St. Louis, Miss.: Federal Reserve Bank of St. Louis. 
Table 1: Summary Statistics for the G5 countries

Panel A: Summary Statistics

\begin{tabular}{|c|c|c|c|c|c|c|c|c|c|c|}
\hline & \multicolumn{2}{|c|}{ United States } & \multicolumn{2}{|c|}{ United Kingdom } & \multicolumn{2}{|c|}{ Germany } & \multicolumn{2}{|c|}{ France } & \multicolumn{2}{|c|}{ Japan } \\
\hline & Mean & $S D$ & Mean & $S D$ & Mean & $S D$ & Mean & $S D$ & Mean & $S D$ \\
\hline age & 42.89 & 2.2882 & 43.78 & 2.5327 & 44.47 & 2.7208 & 45.50 & 1.2529 & 43.15 & 2.5371 \\
\hline \%age65 & 0.1237 & 0.0390 & 0.1377 & 0.0463 & 0.1429 & 0.0463 & 0.1626 & 0.0278 & 0.1225 & 0.0346 \\
\hline \%working & 0.5561 & 0.0240 & 0.5750 & 0.0219 & 0.5802 & 0.0378 & 0.5781 & 0.0195 & 0.5683 & 0.0528 \\
\hline dage & 0.0017 & 0.0018 & 0.0013 & 0.0028 & 0.0018 & 0.0024 & 0.0010 & 0.0031 & 0.0029 & 0.0040 \\
\hline d\%age65 & 0.0089 & 0.0069 & 0.0088 & 0.0078 & 0.0086 & 0.0118 & 0.0052 & 0.0137 & 0.0147 & 0.0164 \\
\hline d\%working & 0.0013 & 0.0050 & 0.0012 & 0.0034 & 0.0021 & 0.0070 & 0.0002 & 0.0039 & 0.0043 & 0.0055 \\
\hline excess & 0.0522 & 0.1953 & 0.0366 & 0.1820 & 0.0302 & 0.2624 & 0.0624 & 0.2442 & 0.0689 & 0.2437 \\
\hline$k$ free $_{t}$ & 0.0420 & 0.0268 & 0.0491 & 0.0357 & 0.0441 & 0.0192 & 0.0506 & 0.0315 & 0.0478 & 0.0194 \\
\hline$e r m_{t}$ & 0.0141 & 0.0146 & 0.0084 & 0.0172 & 0.0085 & 0.0232 & 0.0113 & 0.0167 & 0.0101 & 0.0188 \\
\hline$d$ cons $_{t}$ & 0.0328 & 0.0545 & 0.0178 & 0.0492 & 0.0391 & 0.0329 & 0.0303 & 0.0654 & 0.0424 & 0.0421 \\
\hline
\end{tabular}

Panel B: Selected US Correlations

\begin{tabular}{lcccccc} 
& d\%age65 & d\%working & excess & riskfree & \multicolumn{1}{c}{ term } & \multicolumn{1}{c}{ dcons } \\
dage & 0.5844 & -0.7428 & 0.1508 & -0.4695 & 0.0557 & 0.0300 \\
d\%age65 & & -0.5375 & 0.0536 & -0.5815 & -0.1503 & 0.0485 \\
d\%working & & & -0.1763 & 0.3453 & 0.1591 & -0.0602 \\
excess & & & & -0.2025 & 0.1386 & 0.2358 \\
riskfree & & & & & -0.3120 & -0.1673 \\
term & & & & & & 0.1668
\end{tabular}

Panel C: Selected International Correlations

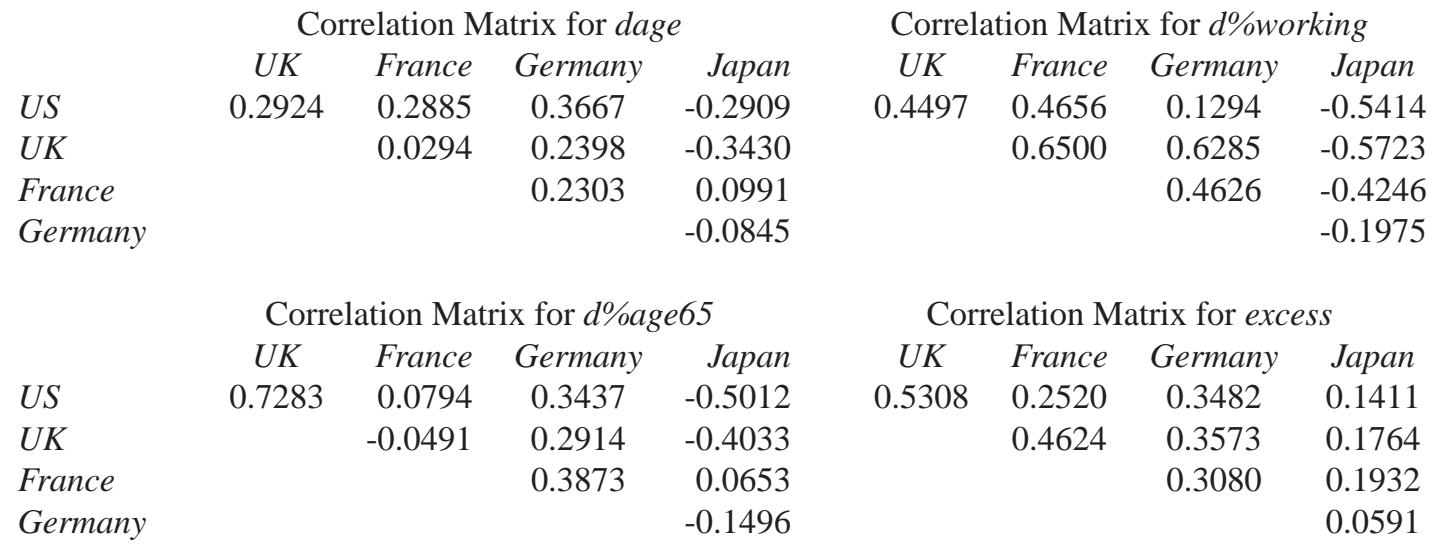

Panel A lists means and standard deviations (SD) for age, the average age of the population over 20 years old; \%age65, the fraction of adults over 65 years old; and \%working, the percentage of people in the [20-64] age class. dage, d\%age65 and $d \%$ working are the log change in age, \%age65 and \%working respectively. The values are calculated over the period 1900-2001 (1999 for population and consumption) for the G5 countries except Japan which covers 1920-2001 (1999). excess is the difference between the continuously compounded total return on the equity index and a short-term riskfree investment. term is the difference between the long bond yield and the short bond term yield. dcons is the continuously compounded change in aggregate consumption. Panel B reports correlations of variables for the US. Panel C reports the correlations across the G5 countries for dage, d\%age65, d\%working and excess. 
Table 2: Small Sample Power Simulations

\begin{tabular}{lccccc}
$10 \%$ Nominal Size & \multicolumn{5}{c}{} \\
$\begin{array}{l}\text { One Sample of Length (Yrs) } \\
\text { Power }\end{array}$ & 99 & 198 & 297 & 396 & 495 \\
& 0.1729 & 0.2411 & 0.3186 & 0.3921 & 0.4575 \\
$\begin{array}{l}\text { Number of Countries } \\
\text { Power }\end{array}$ & 1 & 2 & 3 & 4 & 5 \\
& 0.1729 & 0.2409 & 0.3065 & 0.3700 & 0.4268 \\
& & & & & \\
$5 \%$ Nominal Size & & & & & \\
\hline $\begin{array}{l}\text { One Sample of Length (Yrs) } \\
\text { Power }\end{array}$ & 99 & 198 & 297 & 396 & 495 \\
& 0.1059 & 0.1577 & 0.2138 & 0.2746 & 0.3345 \\
$\begin{array}{l}\text { Number of Countries } \\
\text { Power }\end{array}$ & 1 & 2 & 3 & 4 & 5 \\
& 0.1059 & 0.1561 & 0.2115 & 0.2658 & 0.3146
\end{tabular}

The table reports the power for equations (8) and (9), simulated for one country and for pooled multiple countries. We compare the power of successive samples of 99 years for one country in the row "One Sample of Length (Yrs)" with the power of using pooled cross-sectional country information in the row "Number of Countries," with each country having a sample length of 99 years. We simulate 10,000 small samples to obtain a small sample distribution for the t-statistics. 
Table 3: United States: Regression Results

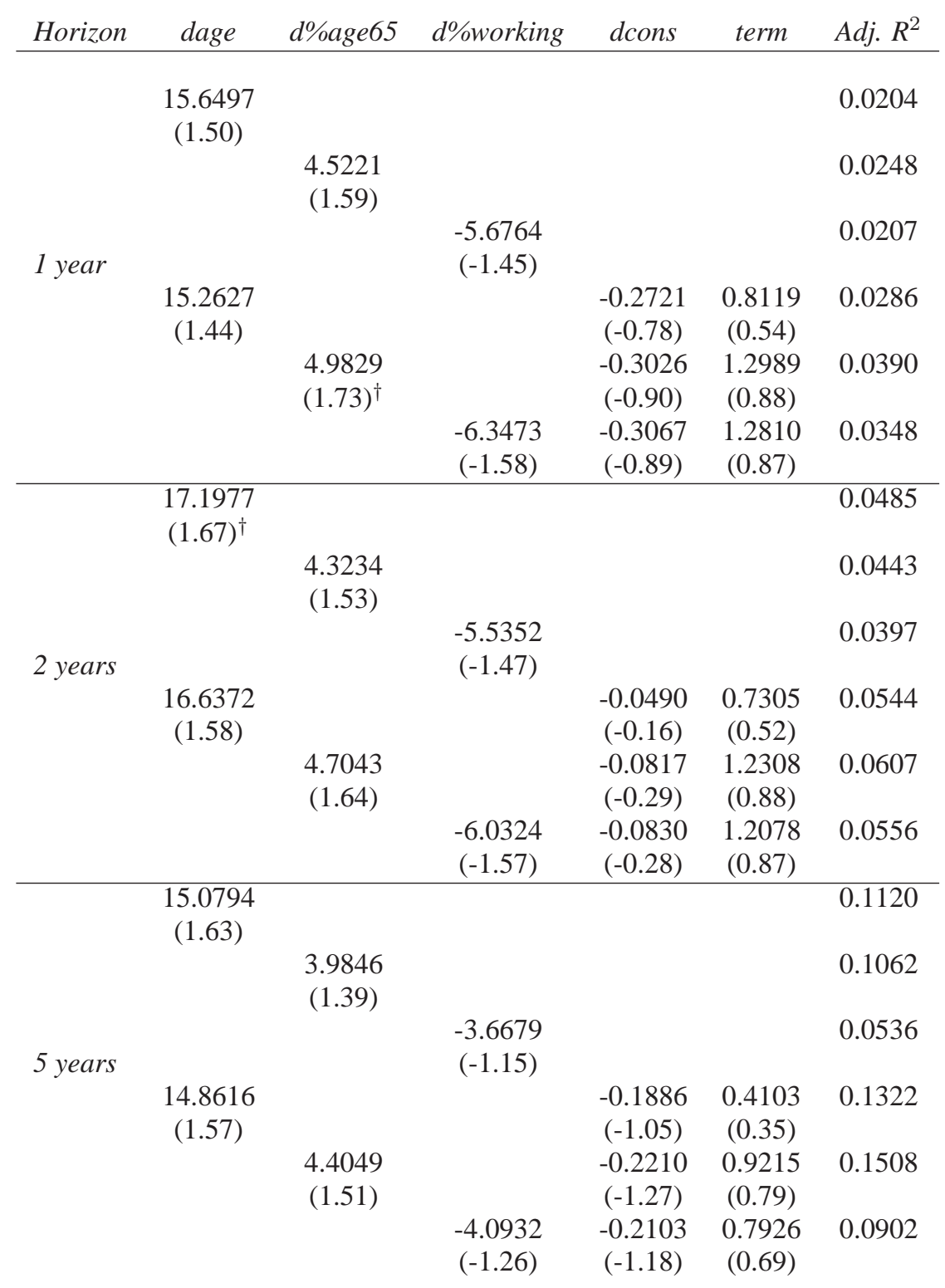

The table lists coefficients and t-statistics for the US regressions over the sample 1900-2001. The explanatory variables are dage, d\%age65 and d\%working. These are the log change of age, the average age of the population over 20 years old, the log change of \%age65, the fraction of adults over 65 years old and the log change of \%working, the percentage of people in the [20-64] age class, respectively. dcons is the continuously compounded change in aggregate consumption and term is the difference between the long bond yield and the short term yield. Standard errors are computed following Hodrick (1992); the t-statistics are reported in parentheses with those significant at the $10 \%$ level denoted by ${ }^{\dagger}$. 
Table 4: United Kingdom: Regression Results.

\begin{tabular}{|c|c|c|c|c|c|c|}
\hline Horizon & dage & d\%age65 & d\%working & dcons & term & Adj. $R^{2}$ \\
\hline \multirow{10}{*}{1 year } & 1.8508 & & & & & 0.0008 \\
\hline & & 4.012 & & & & 0.0290 \\
\hline & & $(2.58) * *$ & & & & \\
\hline & & & -2.7639 & & & 0.0026 \\
\hline & & & $(-0.43)$ & & & \\
\hline & $\begin{array}{c}2.5711 \\
(0.54)\end{array}$ & & & $\begin{array}{c}-0.0687 \\
(-0.28)\end{array}$ & $\begin{array}{c}-0.3361 \\
(-0.29)\end{array}$ & 0.0021 \\
\hline & & 4.7154 & & -0.0559 & -0.9243 & 0.0360 \\
\hline & & $(2.64) * *$ & & $(-0.23)$ & $(-0.84)$ & \\
\hline & & & -3.6746 & -0.1119 & -0.3997 & 0.0048 \\
\hline & & & $(-0.51)$ & $(-0.47)$ & $(-0.36)$ & \\
\hline \multirow{9}{*}{2 years } & 0.6847 & & & & & 0.0002 \\
\hline & & 3.4772 & & & & 0.0437 \\
\hline & & & & & & 00043 \\
\hline & & & $(-0.36)$ & & & \\
\hline & $\begin{array}{c}1.3292 \\
(0.26)\end{array}$ & & & $\begin{array}{c}-0.0016 \\
(-0.01)\end{array}$ & $\begin{array}{c}-0.2738 \\
(-0.22)\end{array}$ & 0.0014 \\
\hline & & 4.0882 & & 0.0023 & -0.7952 & 0.0542 \\
\hline & & $(2.54)^{*}$ & & $(0.01)$ & $(-0.75)$ & \\
\hline & & & -3.1292 & -0.0365 & -0.3764 & 0.1009 \\
\hline & & & $(-0.47)$ & $(-0.20)$ & $(0.38)$ & \\
\hline \multirow{8}{*}{5 years } & $\begin{array}{l}-1.9468 \\
(-0.55)\end{array}$ & & & & & 0.0068 \\
\hline & & $\begin{array}{l}2.7545 \\
(2.25)^{*}\end{array}$ & & & & 0.1002 \\
\hline & & & -2.6819 & & & 0.0196 \\
\hline & & & $(-0.38)$ & & & \\
\hline & $\begin{array}{c}-3.5362 \\
(-0.91)\end{array}$ & & & $\begin{array}{c}-0.0474 \\
(-0.39)\end{array}$ & $\begin{array}{c}0.6692 \\
(0.81)\end{array}$ & 0.0331 \\
\hline & & 2.7130 & & -0.0298 & 0.0608 & 0.1009 \\
\hline & & & -2.3170 & $\begin{array}{c}(-0.25) \\
-0.0563\end{array}$ & $\begin{array}{c}(0.08) \\
0.3048\end{array}$ & 0.0268 \\
\hline & & & $(-0.33)$ & $(-0.49)$ & $(0.50)$ & \\
\hline
\end{tabular}

The table lists coefficients and t-statistics for the UK regressions over the sample 1900-2001. The explanatory variables are dage, d\%age65 and d\%working. These are the log change of age, the average age of the population over 20 years old, the log change of \%age65, the fraction of adults over 65 years old and the log change of \%working, the percentage of people in the [20-64] age class, respectively. dcons is the continuously compounded change in aggregate consumption and term is the difference between the long bond yield and the short term yield. Standard errors are computed following Hodrick (1992); the t-statistics are reported in parentheses with those significant at the 5\% (1\%) level denoted by * (**). 
Table 5: Japan: Regression Results

\begin{tabular}{|c|c|c|c|c|c|c|}
\hline Horizon & dage & d\%age65 & d\%working & dcons & term & $\operatorname{Adj} . R^{2}$ \\
\hline \multirow{9}{*}{1 year } & -13.0242 & & & & & 0.0390 \\
\hline & $(-1.31)$ & -2.5782 & & & & 0.0367 \\
\hline & & $(-1.99)^{*}$ & & & & \\
\hline & & & 11.8108 & & & 0.0704 \\
\hline & & & $(2.33)^{*}$ & & & \\
\hline & $\begin{array}{c}-13.1233 \\
(-1.90)\end{array}$ & & & $\begin{array}{l}1.1288 \\
(1.74)\end{array}$ & $\begin{array}{c}0.0050 \\
(0.34)\end{array}$ & 0.0951 \\
\hline & & -2.5636 & & 1.1566 & 0.0038 & 0.0930 \\
\hline & & $(-1.99)^{*}$ & & (1.79) & $(0.27)$ & \\
\hline & & & $\begin{array}{c}9.5925 \\
(1.63)\end{array}$ & $\begin{array}{l}0.8657 \\
(1.17)\end{array}$ & $\begin{array}{c}-0.0092 \\
(-0.74)\end{array}$ & 0.0942 \\
\hline \multirow{7}{*}{2 years } & -7.6248 & & & & & 0.0211 \\
\hline & & $\begin{array}{c}-1.9184 \\
(-1.10)\end{array}$ & & & & 0.0302 \\
\hline & & & 8.5052 & & & 0.0700 \\
\hline & & & (1.54) & & & \\
\hline & $\begin{array}{c}-9.8369 \\
(-1.11)\end{array}$ & & & $\begin{array}{c}0.4820 \\
(0.97)\end{array}$ & $\begin{array}{c}0.0094 \\
(0.81)\end{array}$ & 0.0589 \\
\hline & & $\begin{array}{c}-2.3576 \\
(-1.32)\end{array}$ & & $\begin{array}{c}0.4829 \\
(0.94)\end{array}$ & $\begin{array}{c}0.0096 \\
(0.87)\end{array}$ & 0.0690 \\
\hline & & & $\begin{array}{l}7.8141 \\
(1.40)\end{array}$ & $\begin{array}{c}0.2624 \\
(0.60)\end{array}$ & $\begin{array}{c}-0.0016 \\
(-0.15)\end{array}$ & 0.0740 \\
\hline \multirow{7}{*}{5 years } & $\begin{array}{c}-2.9667 . \\
(-0.35)\end{array}$ & & & & & 0.0096 \\
\hline & & $\begin{array}{c}-1.1674 \\
(-0.67)\end{array}$ & & & & 0.0341 \\
\hline & & & 5.1007 & & & 0.0609 \\
\hline & & & $(0.13)$ & & & \\
\hline & $\begin{array}{c}-0.4259 \\
(-0.73)\end{array}$ & & & $\begin{array}{c}0.4 / 54 \\
(1.18)\end{array}$ & $\begin{array}{l}0.0128 \\
(1.37)\end{array}$ & 0.1054 \\
\hline & & $\begin{array}{c}-1.8665 \\
(-1.11)\end{array}$ & & $\begin{array}{c}0.4637 \\
(1.09)\end{array}$ & $\begin{array}{c}0.0138 \\
(1.62)\end{array}$ & 0.2036 \\
\hline & & & $\begin{array}{l}2.1595 \\
(0.31)\end{array}$ & $\begin{array}{c}0.4656 \\
(1.59)\end{array}$ & $\begin{array}{c}0.0073 \\
(0.76)\end{array}$ & 0.1364 \\
\hline
\end{tabular}

The table lists coefficients and t-statistics for the Japanese regressions over the sample 1920-2001. The explanatory variables are dage, d\%age65 and d\%working. These are the log change of age, the average age of the population over 20 years old, the log change of \%age65, the fraction of adults over 65 years old and the log change of \%working, the percentage of people in the [20-64] age class, respectively. dcons is the continuously compounded change in aggregate consumption and term is the difference between the long bond yield and the short term yield. In the multivariate regressions, the years 1945-1951 are excluded from the sample because of missing consumption data. Standard errors are computed following Hodrick (1992); the $\mathrm{t}$-statistics are reported in parentheses with those significant at the $5 \%(1 \%)$ level denoted by $*(* *)$. 
Table 6: Pooled Regressions Across the G5 Countries.

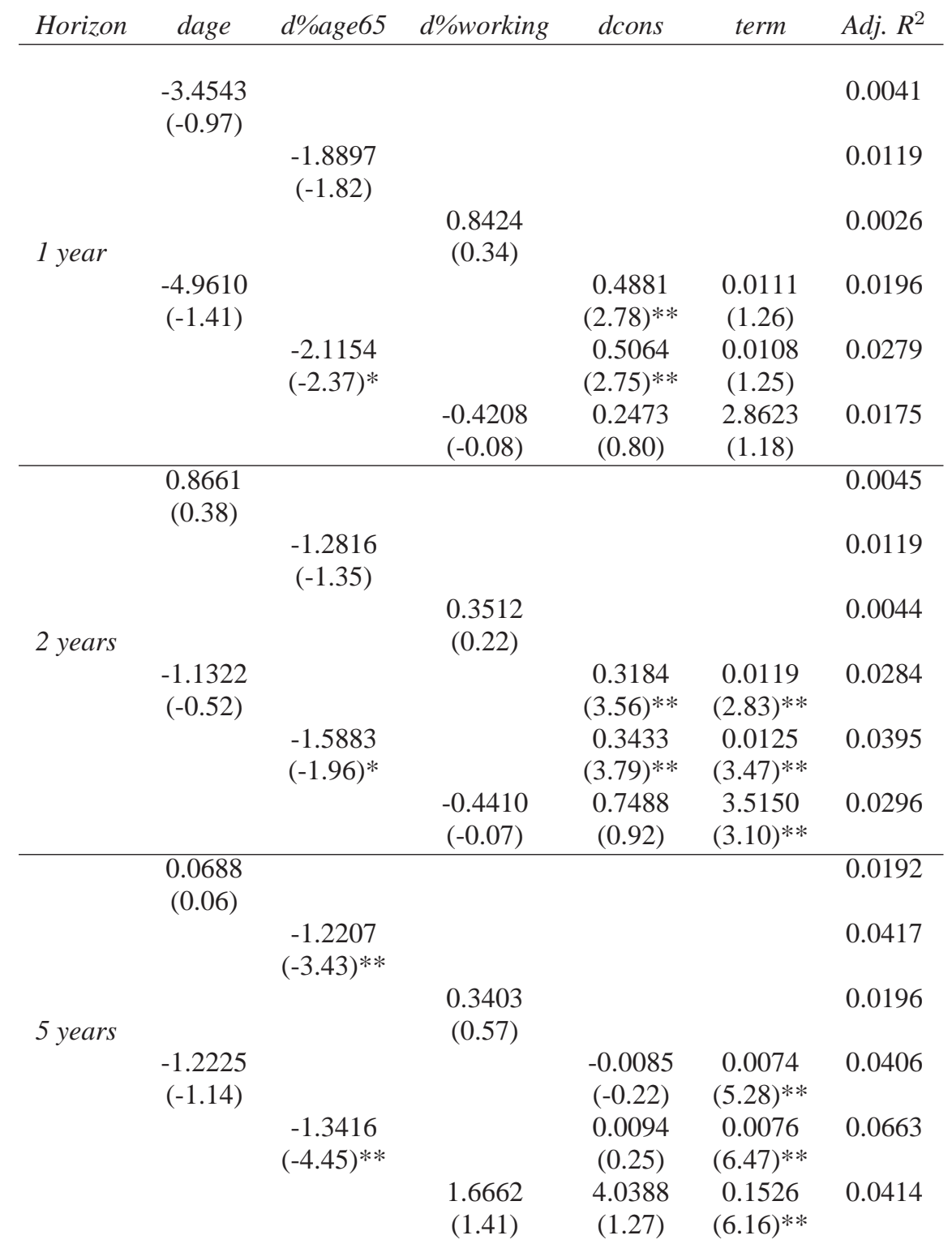

The table lists coefficients and t-statistics for the pooled regressions across the G5 countries over the sample 1920-2001. The explanatory variables are dage, d\%age65 and d\%working. These are the log change of age, the average age of the population over 20 years old, the log change of \%age65, the fraction of adults over 65 years old and the log change of \%working, the percentage of people in the [20-64] age class, respectively. $d c o n s$ is the continuously compounded change in aggregate consumption and term is the difference between the long bond yield and the short term yield. In the univariate regressions, the years 1914-1925 are excluded for Germany because of missing data. In the multivariate regressions, the years 1914-1920 and 1939-1948 for France, 1914-1925 and 1939-1949 for Germany and 1945-1951 for Japan are excluded because of missing data. Standard errors are computed following Hodrick (1992); the t-statistics are reported in parentheses with those significant at the $5 \%(1 \%)$ level denoted by * (**). 
Table 7: Pooled Regression Across 15 Countries

\begin{tabular}{|c|c|c|c|c|c|c|}
\hline Horizon & dage & d\%age65 & d\%working & dcons & term & $\operatorname{Adj} R^{2}$ \\
\hline \multirow{6}{*}{1 year } & 6.2822 & & & & & 0.0161 \\
\hline & & $\begin{array}{c}-4.4649 \\
(-4.91)^{* *}\end{array}$ & & & & 0.0526 \\
\hline & & & $\begin{array}{l}3.8020 \\
(1.54)\end{array}$ & & & 0.0182 \\
\hline & $\begin{array}{c}4.5353 \\
(1.02)\end{array}$ & & & $\begin{array}{l}-1.8295 \\
(-4.61)^{* *}\end{array}$ & $\begin{array}{l}0.3468 \\
(1.64)^{*}\end{array}$ & 0.0469 \\
\hline & & $\begin{array}{c}-4.1088 \\
(-5.54)^{* *}\end{array}$ & & $\begin{array}{l}-1.6330 \\
(-4.12)^{* *}\end{array}$ & $\begin{array}{c}0.4434 \\
(2.10)^{* *}\end{array}$ & 0.0782 \\
\hline & & & $\begin{array}{c}2.5963 \\
(1.19) \\
\end{array}$ & $\begin{array}{c}-1.7928 \\
(-4.71)^{* *} \\
\end{array}$ & $\begin{array}{l}0.3693 \\
(1.77)^{*}\end{array}$ & 0.0477 \\
\hline \multirow{6}{*}{2 years } & $\begin{array}{c}5.9676 \\
(1.51)\end{array}$ & & & & & 0.0339 \\
\hline & & $\begin{array}{c}-4.1374 \\
(-4.84)^{* *}\end{array}$ & & & & 0.0968 \\
\hline & & & $\begin{array}{l}3.7556 \\
(1.72)^{*}\end{array}$ & & & 0.0385 \\
\hline & $\begin{array}{l}4.0460 \\
(1.20)\end{array}$ & & & $\begin{array}{c}-1.9366 \\
(-6.08)^{* *}\end{array}$ & $\begin{array}{c}0.2268 \\
(1.25)\end{array}$ & 0.1029 \\
\hline & & $\begin{array}{c}-3.7071 \\
(-5.63)^{* *}\end{array}$ & & $\begin{array}{c}-1.7570 \\
(-5.47)^{* *}\end{array}$ & $\begin{array}{l}0.3235 \\
(1.73)^{*}\end{array}$ & 0.1541 \\
\hline & & & $\begin{array}{c}2.4473 \\
(1.37)\end{array}$ & $\begin{array}{c}-1.9036 \\
(-5.99) * *\end{array}$ & $\begin{array}{c}0.2469 \\
(1.34)\end{array}$ & 0.1046 \\
\hline \multirow{6}{*}{5 years } & $\begin{array}{c}3.0178 \\
(1.14)\end{array}$ & & & & & 0.0890 \\
\hline & & $\begin{array}{c}-2.75 \\
(-3.99)^{* *}\end{array}$ & & & & 0.1646 \\
\hline & & & $\begin{array}{c}3.1758 \\
(1.4968)\end{array}$ & & & 0.1055 \\
\hline & $\begin{array}{l}1.8132 \\
(0.91)\end{array}$ & & & $\begin{array}{c}-1.3995 \\
(-7.24)^{* *}\end{array}$ & $\begin{array}{c}0.0550 \\
(0.4472)\end{array}$ & 0.1949 \\
\hline & & $\begin{array}{c}-2.3052 \\
(-5.33)^{* *}\end{array}$ & & $\begin{array}{c}-1.2556 \\
(-6.63)^{* *}\end{array}$ & $\begin{array}{l}0.1203 \\
(0.95)\end{array}$ & 0.2471 \\
\hline & & & $\begin{array}{l}1.9217 \\
(1.54)\end{array}$ & $\begin{array}{c}-1.3459 \\
(-6.99)^{* *}\end{array}$ & $\begin{array}{l}0.0558 \\
(0.44)\end{array}$ & 0.2007 \\
\hline
\end{tabular}

The table lists coefficients and t-statistics for the pooled regressions across the following countries: Australia, Austria, Belgium, Canada, Denmark, France, Germany, Italy, Japan, the Netherlands, Spain, Sweden, Switzerland, the United Kingdom and the United States. The sample period is 1970-2000 and the data is monthly. The explanatory variables are dage, d\%age65 and d\%working. These are the log change of age, the average age of the population over 20 years old, the log change of \%age65, the fraction of adults over 65 years old and the log change of \%working, the percentage of people in the [20-64] age class. dcons is the continuously compounded change in aggregate consumption and term is the difference between the long bond yield and the short term yield. Standard errors are computed following Hodrick (1992); the t-statistics are reported in parentheses with those significant at the 5\% (1\%) level denoted by ***). 


\section{Table 8: Pooling by Social Security}

Panel A: Ranking of Countries

Low Benefit High Benefit

$\begin{array}{llll}\text { Belgium } & 1.29 & \text { Switzerland } & 1.97 \\ \text { Netherlands } & 1.18 & \text { Italy } & 1.73 \\ \text { UK } & 1.17 & \text { Austria } & 1.71 \\ \text { US } & 1.08 & \text { France } & 1.64 \\ \text { Australia } & 1.03 & \text { Germany } & 1.46 \\ \text { Denmark } & 1.02 & \text { Spain } & 1.43 \\ \text { Sweden } & 0.96 & \text { Japan } & 1.43 \\ \text { Canada } & 0.79 & & \end{array}$

Panel B: Demographic Predictive Regressions

Low Benefit Countries High Benefit Countries

\begin{tabular}{|c|c|c|c|c|c|c|}
\hline Horizon & dage & d\%age65 & d\%working & dage & d\%age65 & d\%working \\
\hline \multirow[t]{2}{*}{1 year } & 6.9318 & -3.0288 & -2.7727 & & 46206 & 7.0535 \\
\hline & (1.14) & $(-2.73)^{* *}$ & $(-1.03)$ & $(0.13)$ & $(-4.60) * *$ & $(1.89)^{*}$ \\
\hline \multirow[t]{2}{*}{2 years } & 7.7230 & -2.4472 & -2.3594 & -1.1276 & -4.1875 & 6.0736 \\
\hline & (1.83) & $(-2.45)^{* *}$ & $(-1.16)$ & $(-0.19)$ & $(-4.33) * *$ & (1.57) \\
\hline \multirow[t]{2}{*}{5 years } & 3.7043 & -1.7427 & -1.2778 & -2.8323 & -2.4494 & 4.1371 \\
\hline & $(1.46)$ & $(-2.59) * *$ & $(-0.82)$ & $(-0.75)$ & $(-2.75)^{* *}$ & $(1.26)$ \\
\hline
\end{tabular}

We divide countries into two groups, low and high social security benefit countries, following equation (10). Panel A lists the average values of equation (10) and the countries within each group. Panel B reports coefficients and Hodrick (1992) t-statistics in parentheses of the trivariate pooled regressions across the two groups. In each entry, we regress the excess returns onto the demographic variable $z_{t}$, together with $d c o n s$ and term, but only report the demographic coefficient and t-statistic. The sample period is 1970-2000 and the data is monthly. T-statistics significant at the 5\% (1\%) level denoted by * (**). 
Table 9: Pooling by Market Development

Panel A: Ranking of Countries

Low Development High Development

$\begin{array}{lrll}\text { Spain } & 4.07 & \text { Switzerland } & 0.79 \\ \text { Belgium } & 4.89 & \text { Japan } & 1.28 \\ \text { Denmark } & 5.69 & \text { UK } & 1.53 \\ \text { Germany } & 5.78 & \text { Canada } & 1.62 \\ \text { Sweden } & 5.82 & \text { US } & 1.88 \\ \text { France } & 7.15 & \text { Australia } & 2.55 \\ \text { Italy } & 10.17 & \text { Netherlands } & 3.01 \\ \text { Austria } & 19.79 & & \end{array}$

Panel B: Demographic Predictive Regressions

Low Market Development Countries High Market Development Countries

\begin{tabular}{lcccccc} 
Horizon & dage & d\%age65 & d\%working & dage & d\%age65 & d\%working \\
\hline \multirow{2}{*}{ 1 year } & -8.3531 & -5.3152 & 10.0431 & 8.6819 & -2.8809 & -3.9944 \\
& $(-0.93)$ & $(-5.09)^{* *}$ & $(2.78)^{* *}$ & $(1.43)$ & $(-2.17)^{*}$ & $(-1.46)$ \\
\multirow{2}{*}{ years } & -2.1119 & -4.4127 & 9.3995 & 5.7231 & -3.4172 & -3.7172 \\
& $(-0.31)$ & $(-4.43)^{* *}$ & $(2.61)^{* *}$ & $(1.16)$ & $(-3.22)^{* *}$ & $(-1.76)$ \\
\multirow{2}{*}{5 years } & 2.1971 & -2.6421 & 7.5059 & 2.0938 & -2.5104 & -2.6819 \\
& $(0.43)$ & $(-3.31)^{* *}$ & $(2.13)^{*}$ & $(0.79)$ & $(-3.60)^{* *}$ & $(-1.90)$
\end{tabular}

We divide countries into two groups, low and high social security benefit countries, following equation (11). Panel A lists the average values of equation (11) and the countries within each group. Panel B reports coefficients and Hodrick (1992) t-statistics in parentheses of the trivariate pooled regressions across the two groups. In each entry, we regress the excess returns onto the demographic variable $z_{t}$, together with $d c o n s$ and term, but only report the demographic coefficient and t-statistic. The sample period is 1970-2000 and the data is monthly. T-statistics significant at the 5\% (1\%) level denoted by * (**). 

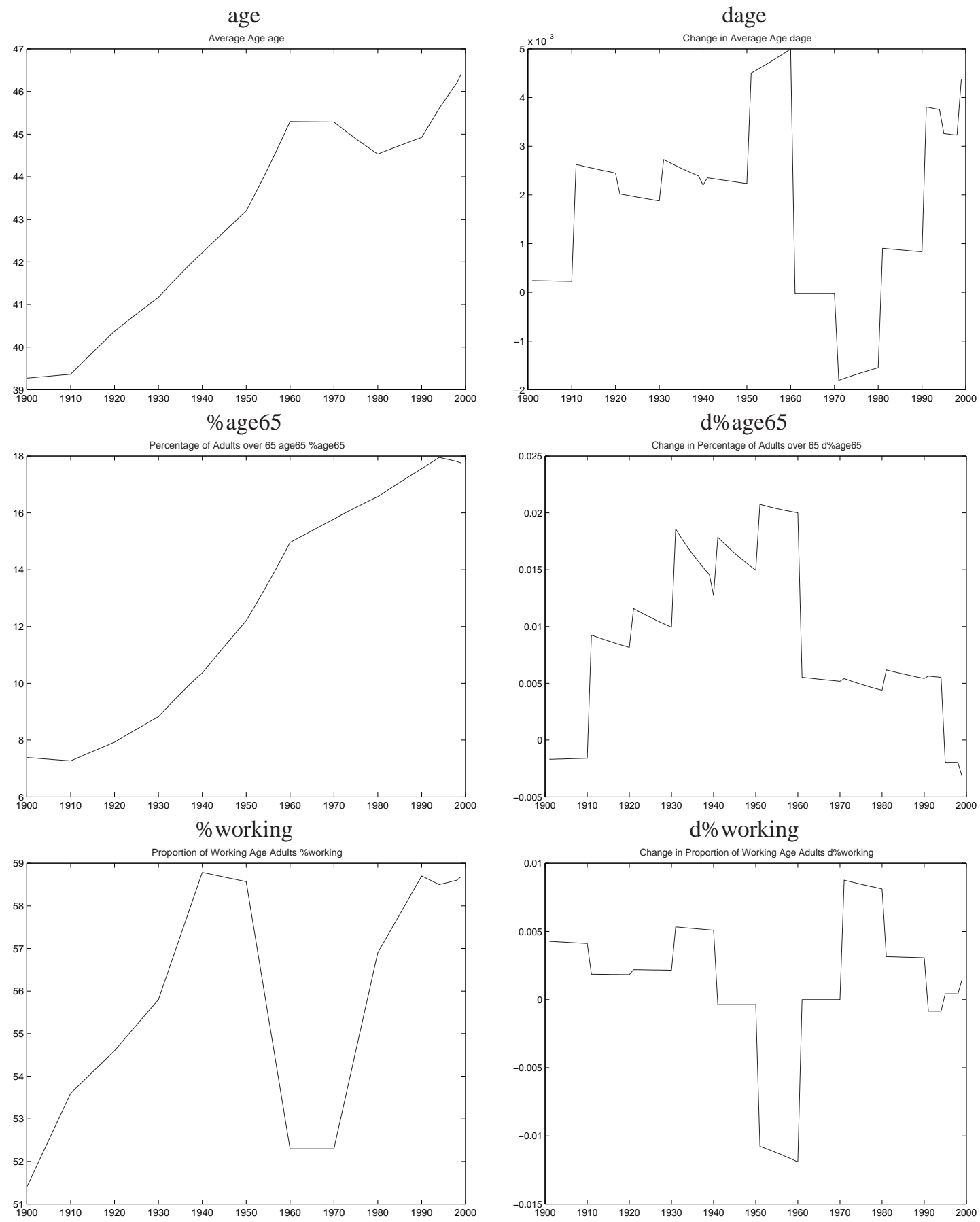

The graphs show the trends of demographic variables in the US over the period 1900-1999. age is the weighted average age of the population over 20 years old. \%age65 is the percentage of adults over 65 years old and \%working represents the percentage of people in the [20-64] age class. dage, d\%age65 and $d \%$ working are the log annual changes of those variables.

Figure 1: Demographic trends in the United States 
Panel A: Average Age

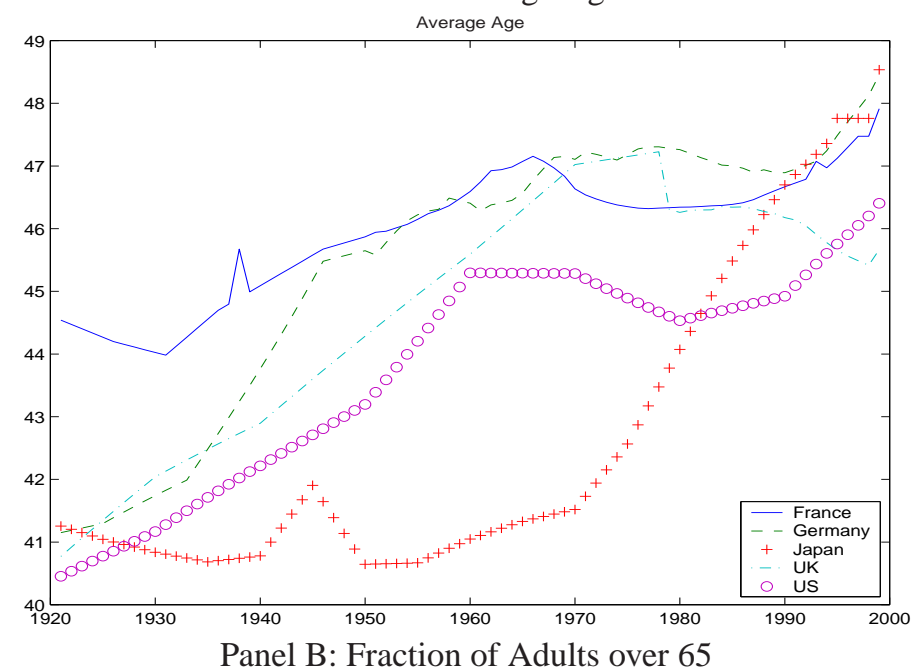

Percentage of People over 65

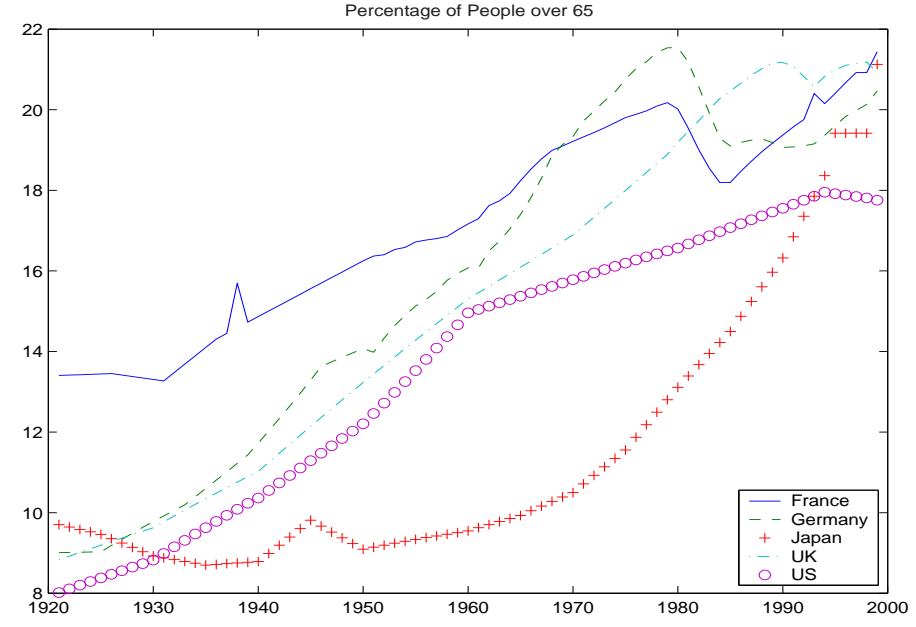

Panel C: Fraction of the Working Population

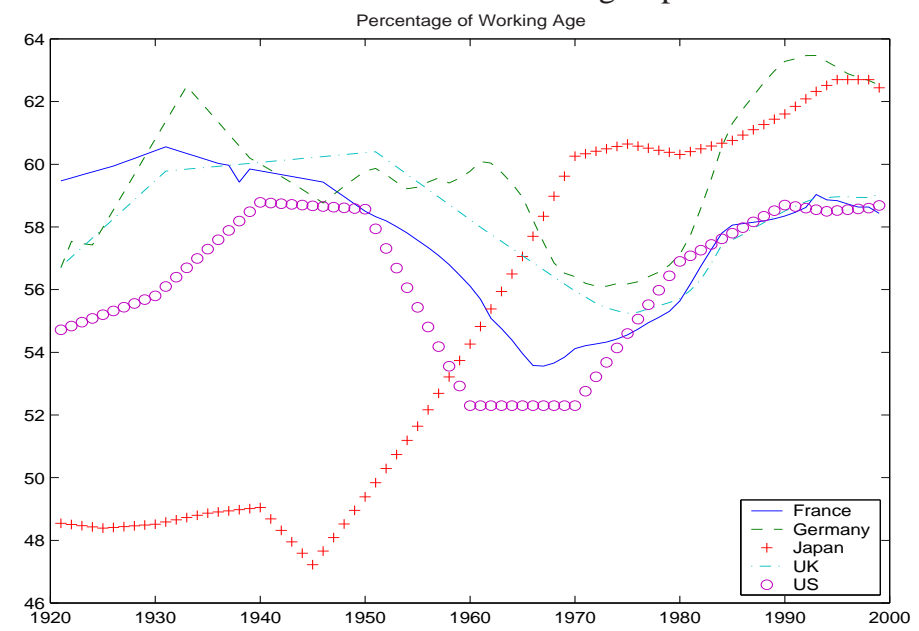

Plots of the average age age (Panel A), the fraction of adults over 65 in the population \%age65 (Panel B) and the proportion of people in the [20-64] age class \%working (Panel C) for the G5 countries over the period 1920-1999.

Figure 2: Demographic Variables in 5 Developed Countries 
Panel A: dage

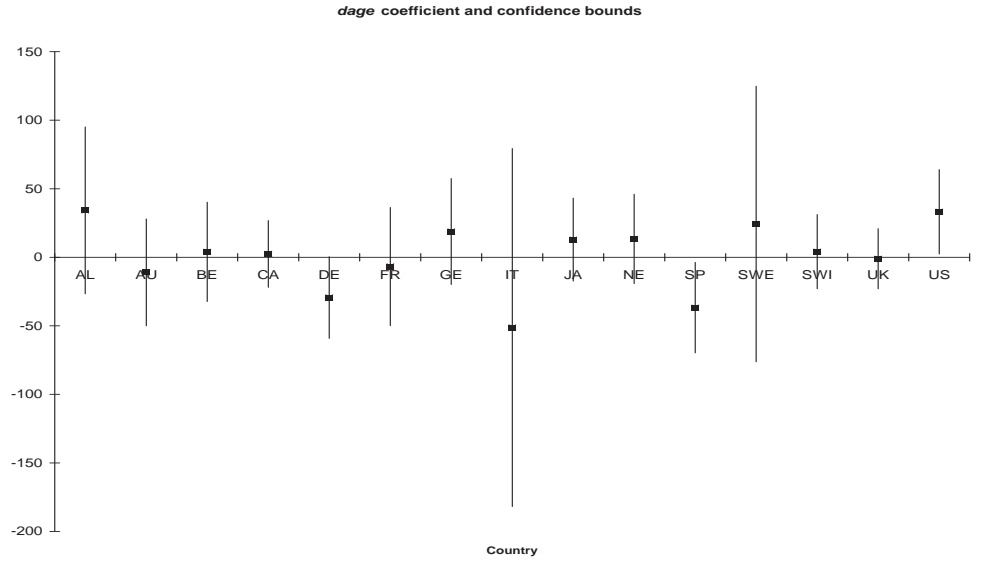

Panel B: d\%age65

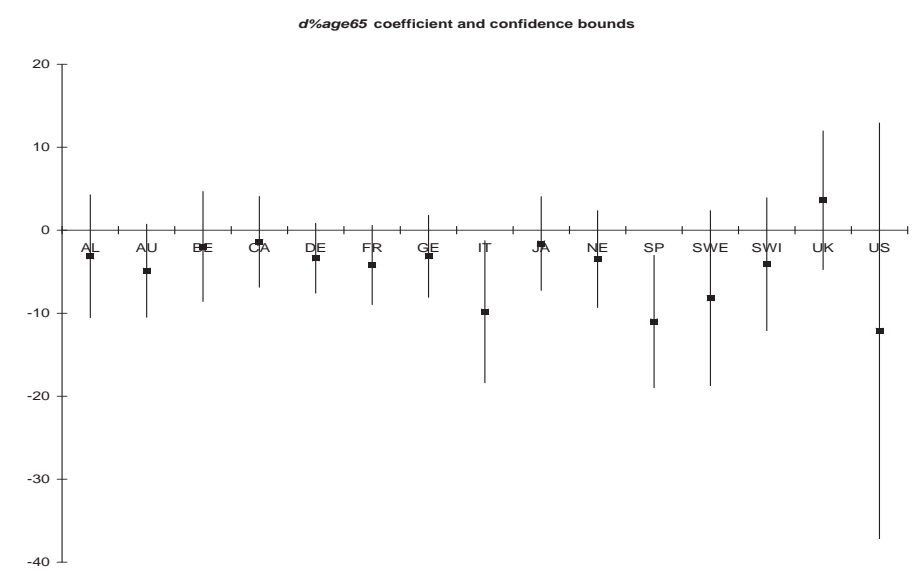

Panel C: d\%working

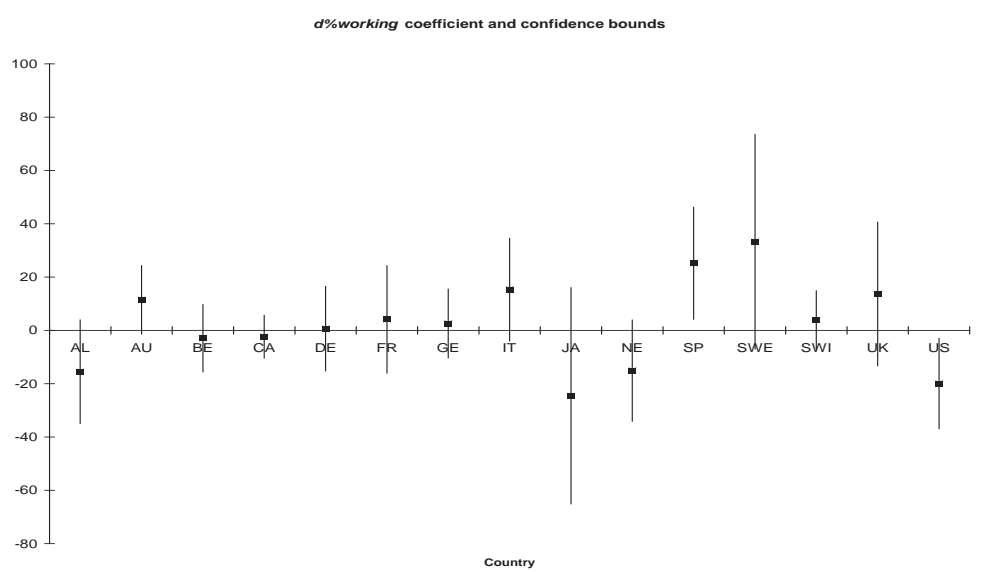

The plots report the value of the coefficients (squares) and 95\% confidence bounds (vertical lines) for the demographic variables dage (Panel A), d\%age65 (Panel B) and d\%working (Panel C) in the trivariate regressions which control for dcons and term, for each of the following countries: Australia (AL), Austria (AU), Belgium (BE), Canada (CA), Denmark (DE), France (FR), Germany (GE), Italy (IT), Japan (JA), the Netherlands (NE), Spain (SP), Sweden (SWE), Switzerland (SWI), the United Kingdom (UK) and the United States (US). The sample period is 1970-2001 and the forecast horizon is 1 year.

Figure 3: Coefficients and Confidence Bounds for 15 Countries 